
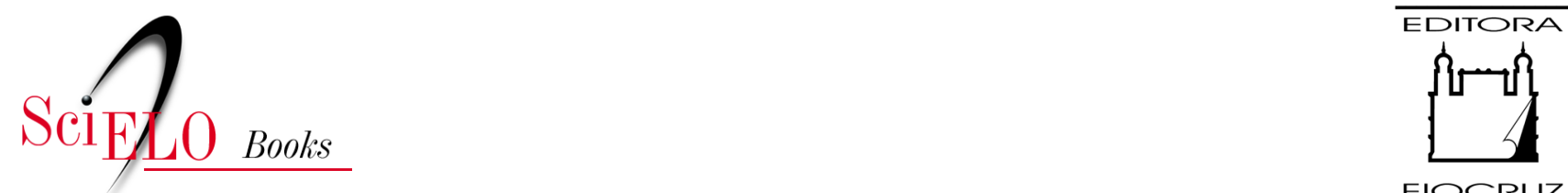

FIOCRUZ

\title{
2. Os recursos físicos de saúde no Brasil um olhar para o futuro
}

\author{
Isabela Soares Santos \\ Luisa Regina Pessôa \\ Juliana Pires Machado \\ Ana Cristina Marques Martins \\ Claudia Risso de Araujo Lima
}

\section{SciELO Books / SciELO Livros / SciELO Libros}

SANTOS, I.S., PESSÔA, L.R., MACHADO, J.P., MARTINS, A.C.M., and LIMA, C.R.A. Os recursos físicos de saúde no Brasil: um olhar para o futuro. In: NORONHA, J.C., LIMA, L.D., CHORNY, A.H., DAL POZ, M.R., and GADELHA, P., eds. Brasil Saúde Amanhã: dimensões para o planejamento da atenção à saúde [online]. Rio de Janeiro: Editora FIOCRUZ, 2017, pp. 63-111. ISBN: 978-65-5708-090-0. https://doi.org/10.7476/9786557080900.0004.

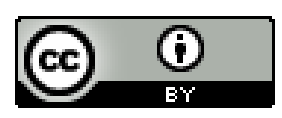

All the contents of this work, except where otherwise noted, is licensed under a Creative Commons Attribution 4.0 International license.

Todo o conteúdo deste trabalho, exceto quando houver ressalva, é publicado sob a licença Creative Commons Atribição 4.0.

Todo el contenido de esta obra, excepto donde se indique lo contrario, está bajo licencia de la licencia $\underline{\text { Creative }}$ Commons Reconocimento 4.0. 


\title{
OS RECURSOS FÍSICOS DE SAÚDE NO BRASIL: UM OLHAR PARA O FUTURO'
}

\author{
Isabela Soares Santos \\ Luisa Regina Pessôa \\ Juliana Pires Machado \\ Ana Cristina Marques Martins \\ Claudia Risso de Araujo Lima
}

Mapear a atual capacidade instalada de saúde no Brasil constitui um caminho estratégico de identificação e análise das necessidades de investimento para atender às demandas advindas das mudanças sociodemográficas, econômicas e epidemiológicas previstas para os próximos vinte anos até 2034 .

Cabe uma discussão semântica para identificar e nomear nosso objeto, conhecido como oferta de serviços de saúde, capacidade instalada de saúde, estrutura de serviços de saúde e, por fim, a denominação que optamos por utilizar: recursos físicos da saúde. Ainda é escassa a discussão acadêmica sobre qual o melhor termo, razão pela qual será dada uma breve explicação do motivo que nos levou a essa escolha para designar a capacidade instalada de saúde. Recursos físicos de saúde são parte da oferta de serviços da saúde, que engloba:

- recursos físicos: compreendem as edificações, suas instalações, equipamentos e mobiliários (Pessôa, 1996) que no Cadastro Nacional de Estabelecimentos de Saúde (CNES) estão expressos em leitos, serviços, equipamentos, entre outros;

- recursos humanos: quadro de profissionais existentes;

- recursos cognitivos/tecnológicos: conhecimento acumulado para exercer as atividades profissionais específicas visando operacionalizar e gerenciar a capacidade instalada;

- recursos materiais: insumos diversos, medicamentos e material médico-cirúrgico;

- recursos financeiros: custeio e capital;

- recursos de poder: viabilizam a inserção na rede de atenção, de modo credenciado e sustentável.

Não serão analisados dados sobre toda a oferta de serviços de saúde, uma vez que esta pressupõe a existência dos demais recursos relacionados anteriormente. Ainda, consideramos que os recursos humanos e os profissionais específicos da assistência (enfermeiros, médicos e outros profissionais da saúde) já estão contemplados em outro capítulo nesta obra.

\footnotetext{
${ }^{1}$ Agradecemos a disponibilidade para discussão e contribuição dos especialistas da equipe de Claudio Noronha na Coordenação de Prevenção e Vigilância do Instituto Nacional de Câncer José Alencar Gomes da Silva (Conprev/ Inca) e do pesquisador Walter Mendes Jr. do Departamento de Administração e Planejamento em Saúde da Escola Nacional de Saúde Pública Sergio Arouca da Fundação Oswaldo Cruz.
} 
Os recursos físicos compõem apenas uma das dimensões do parque tecnológico de saúde no Brasil, já que tecnologia de saúde envolve todas as formas de conhecimento que podem ser aplicadas para solução ou redução dos problemas de saúde de indivíduos ou populações. Um dos principais problemas atuais em grande parte dos hospitais brasileiros, no contexto de discussão das possibilidades de prospecção tecnológica, é o do baixíssimo número de profissionais capacitados voltados para a gestão do parque tecnológico da saúde - tanto para a avaliação tecnológica como para a incorporação de tecnologias - ou seja, pesquisadores, gerentes, profissionais da saúde e técnicos.

A incorporação de novas tecnologias de saúde no Brasil, em especial na rede pública, é muitas vezes realizada de forma inadequada, em face da fragilidade dessas incorporações. A gravidade dessa situação é ressaltada no resultado de auditoria do Tribunal de Contas da União, com ampla cobertura da mídia, no que se refere ao tema da assistência hospitalar no SUS: baseado no estudo abrangendo 116 hospitais públicos com mais de 50 leitos, que concentram aproximadamente 27.614 leitos (8,6\% do total de leitos na rede pública), em todos os estados da federação, identificaram-se os motivos para bloqueio ou indisponibilidade de leitos e serviços para uso da população (TCU, 2013; Anexo).

Parte dos problemas enfrentados na rede de saúde em relação aos seus recursos físicos é reflexo da carência de trabalhadores da construção civil e na área de máquinas e equipamentos envolvidos no processo operacional e de manutenção. Apesar de os estudos recentes não serem específicos do setor Saúde, a situação nesse setor pode ser mais grave, dada a insuficiente formação específica para a área. A carência desses profissionais é agravada pela insuficiência de médicos, enfermeiros e outros profissionais da saúde, caracterizando um problema a ser enfrentado pelas políticas públicas, com influência tanto sobre as tecnologias em uso como na incorporação de novas tecnologias.

\section{Contexto}

Em relação a expansão e transformação da estrutura de serviços de saúde do Brasil, envolvendo unidades públicas e privadas, é importante compreender os desafios do cenário atual em relação ao conjunto de recursos assistenciais. "É preciso apreender sua historicidade, seus determinantes, os valores e atores envolvidos, com vistas à elaboração de propostas que possam ser, de fato, estruturantes e coerentes com o conjunto das políticas públicas e de saúde" (Brasil, 2004c: 9).

Nesse contexto, um dos desafios é estabelecer ações para que haja uma melhor sinergia entre os valores e atores envolvidos, como a indústria de medicamentos, equipamentos e insumos, os serviços prestadores de assistência direta públicos e privados, as empresas prestadoras de serviços profissionais e de consultorias, os aparelhos formadores de profissionais, as entidades de pesquisa, os profissionais, as operadoras, as empresas que compram planos privados de saúde para seus trabalhadores, o governo e o cidadão (Vecina Neto \& Malik, 2007).

A rápida e crescente transformação da assistência médico-hospitalar a partir da década de 1980 e os avanços da tecnologia - sobretudo dos recursos para diagnóstico e terapia - têm ocorrido associados a um crescimento desordenado dos serviços intra-hospitalares, gerando reflexos na organização funcional das unidades de saúde. Esse problema tem se agravado pela falta de 
continuidade dos processos ao longo das diversas gestões de diretores de hospitais, secretários de saúde, interpostas no decorrer das décadas, de modo que a cada nova gestão se inicia um novo e diferente processo gerencial realizado por uma nova equipe. Os casos de maior continuidade são aqueles nos quais se cria uma inteligência na unidade, com funcionários estáveis e capacitados para realizar esse processo.

Ao mesmo tempo, a incorporação de máquinas e equipamentos na assistência à saúde cada vez mais requer espaços e instalações sofisticados e o cumprimento de muitas exigências de segurança. Sem mão de obra qualificada essa incorporação fica incompleta e o equipamento pode, muitas vezes, permanecer encaixotado. Tal questão nos leva à necessidade de dimensionar quantos equipamentos existentes estão efetivamente em uso. Em geral, os gestores de saúde investem recursos na aquisição de equipamentos e na construção de instalações físicas de saúde que nem sempre condizem com a quantidade e especificidade necessária de profissionais da saúde.

O trabalho de Pessôa (2009) informa que em países desenvolvidos cerca de 25 a $50 \%$ dos parques de equipamentos não estão sendo totalmente utilizados. As razões para o uso ineficiente são variadas e incluem: dificuldades na aquisição de materiais de consumo e de peças de reposição; falta de recursos humanos treinados; inadequada infraestrutura para instalação e operação ou demanda muito baixa de pacientes (Pessôa, 2009).

A desatenção a questões de conjugação da dimensão operacional ao pensamento estratégico de planejamento e organização da atenção à saúde acarreta o surgimento de problemas mesmo entre os aparelhos em uso, levando a situações de desperdício. Diante dessa situação, consideramos estratégico estabelecer prioridades de investimento considerando os aparelhos em uso ou sem uso e as lacunas de existência de aparelhos. Sempre que possível, esse olhar estará presente na avaliação sobre a disponibilidade de recursos físicos de saúde.

Considerando os dias atuais, é indiscutível que o processo de incorporação de tecnologias na assistência médico-hospitalar ocorre de modo acelerado, irreversível e implacável. Conforme Pessôa (2005), tal processo é marcado por quatro dimensões "estruturantes" que lhe imprimem maior grau de complexidade:

- a incorporação de máquinas e equipamentos não substitui a mão de obra existente;

- a incorporação de tecnologias para o apoio ao diagnóstico é cumulativa - uma nova tecnologia não prescinde da anterior;

- a incorporação de tecnologias de saúde pressupõe a formação e capacitação constante de operadores das mesmas; e

- a incorporação de tecnologias de saúde pressupõe cuidados redobrados com "a saúde" do parque tecnológico, tendo em vista sua confiabilidade.

A mesma dinâmica vem impulsionando as transformações das estruturas físicas e tecnológicas do setor Saúde, trazendo à tona dilemas profundos no que concerne aos desafios da alocação de recursos para tal finalidade. Considerando que países em desenvolvimento geralmente têm escassez de recursos e limitações de orçamento para a realização de investimentos em aquisição, operação 
e manutenção de equipamentos ou tecnologias médico-hospitalares, torna-se recomendável que a decisão de comprar um novo equipamento não se baseie apenas no conceito do que seria "bom ter", mas, sobretudo, no que seria "necessário ter" e no que seria "possível operar". Assim, ao lado dos recursos físicos existentes, é preciso considerar o processo de formação de profissionais da saúde e afins.

Outro ponto importante de ponderação sobre os recursos físicos de saúde é o das altas taxas de cobertura de plano privado de saúde da população brasileira. As taxas de coberturas estão associadas aos níveis de escolaridade, de renda e de emprego (sobretudo o formal), fazendo com que as capitais e as demais regiões mais populosas e desenvolvidas do país tenham maiores parcelas da população com plano privado. Essa população usa grande parte dos serviços referenciados pelo plano, que são privados, mas muitas vezes esses serviços atendem tanto ao SUS como aos planos e a quem puder pagar diretamente do bolso. Nesse sentido, o dimensionamento da distribuição da oferta de recursos físicos deve contemplar tanto a distribuição geográfica como a distribuição público-privada dos recursos.

Além dessas questões, é imprescindível considerar o processo de transição demográfica que transforma a sociedade brasileira, com crescimento mais lento do número de crianças e adolescentes e aumento da população em idade ativa e de pessoas idosas, alterando a estrutura etária da população (Oliveira \& Oneill, 2013). São fatores determinantes dos observados declínios dos níveis gerais de mortalidade e das quedas expressivas da fecundidade que alteram o padrão de uso e a necessidade de recursos físicos de saúde.

Esse processo não ocorre de forma similar nas regiões do país; a necessidade de oferta e disponibilidade de recursos físicos também é diferente entre as regiões. Tome-se como exemplo o processo tardio de envelhecimento das populações das regiões Norte e Nordeste do país, paralelamente à transição demográfica nas regiões Sul e Sudeste do país e as correspondentes consequências das mudanças no perfil de morbidade dessa população. No momento atual, os estados do Norte e Nordeste poderiam estar se preparando e elaborando estratégias para melhor equacionar seus problemas quando alcançarem o ponto da transição demográfica em que as regiões Sul e Sudeste já se encontram.

Ademais, ao pensar na estrutura de oferta, é preciso considerar uma nova distribuição qualitativa dos serviços, extrapolando as especialidades clássicas e prevendo a necessidade de maior oferta a populações mais envelhecidas, ou a indivíduos portadores de doenças crônicas, múltiplas morbidades ou necessidades especiais, que ganharam maior sobrevida nas últimas décadas (por exemplo, os bebês com autismo, síndrome de Down etc.). As transições demográfica e epidemiológica muito provavelmente levarão ao aumento, no futuro, da demanda por serviços como fisioterapia e logopedia, por exemplo, ou mesmo por serviços disponíveis para pacientes fora de possibilidades terapêuticas e que requerem cuidados paliativos.

O aumento da longevidade interfere na estrutura das famílias: no início do século XX era comum pelo menos um membro da família ser portador de tuberculose; no início do século XXI, as famílias dispõem de pelo menos um idoso que requer apoio. São mudanças na sociedade que demandam lugares para os idosos morarem que não sejam hospitais, mas com estrutura de apoio que reconfigure a atenção à saúde do idoso: novas formas de homecare que sirvam para idosos que morem sozinhos 
e maior atenção aos cuidadores, profissionais ou familiares cada vez mais necessários. Esse já é um problema da sociedade brasileira das regiões Sul e Sudeste do país, mas em razão do processo de mudança sociodemográfica e de morbimortalidade, ainda há tempo para prevenir as regiões Norte e Nordeste dos acontecimentos previstos com estrutura para enfrentá-los em melhores condições.

Assim, as mudanças demográficas ocorridas nos últimos anos, associadas às mudanças no padrão de morbimortalidade da população brasileira, são fatores conjunturais essenciais na análise das necessidades futuras da estrutura dos serviços de saúde.

Em relação ao padrão de morbimortalidade da população brasileira, observa-se que nas análises da situação de saúde da população brasileira identificam-se avanços importantes traduzidos na redução significativa de alguns problemas, com destaque para as retrações observadas nas taxas de mortalidade infantil, na taxa de desnutrição em crianças e na ocorrência das doenças infectocontagiosas, parasitárias e as imunopreveníveis (Oliveira \& Oneill, 2013; Barreto, 2013, Luna \& Silva, 2013).

Todavia, é uma tendência o aumento da obesidade em todas as faixas etárias. A obesidade está relacionada à ocorrência de doenças cardiovasculares, hipertensão, diabetes e outras. As doenças cardiovasculares, às quais se atribuem reduções na taxa de mortalidade (TM), ainda são uma das principais causas de óbito entre os brasileiros. Além disso, permanecem como um importante fator de morbidade, levando a uma grande demanda por serviços, inclusive internações hospitalares. O tratamento dessas doenças, dentre elas a obesidade, deve estar direcionado para políticas e ações de promoção de dietas saudáveis, estímulo à atividade física e inserção na vida social. Ao mesmo tempo, muitas vezes esses problemas de saúde estão associados à necessidade de atividades de reabilitação e de intervenções complexas quando da instalação da doença e suas sequelas (Barreto, 2012; Luna \& Silva, 2013).

Um grupo de doenças que tem impacto importante no perfil de morbimortalidade da população brasileira é o do câncer. Os diferentes tipos de câncer apresentam distintas tendências de mortalidade, algumas de redução e outras de aumento. Ressalta-se o aumento das TMs de câncer de próstata e a redução das TMs de câncer de estômago entre os homens. Nas mulheres, observa-se aumento das TMs de câncer de mama e de pulmão (Barreto, 2012; Luna \& Silva, 2013).

Outra questão que deve ser analisada em relação à estrutura de serviços de saúde é a demanda gerada pelos eventos provocados por causas externas (violências e acidentes). Nas últimas décadas, as diversas formas de violência e lesões estão entre os problemas de saúde que mais afligem os brasileiros. Os dois principais componentes, homicídios e acidentes de trânsito, são responsáveis por taxas de mortalidade muito superiores às de países desenvolvidos. Esses agravos, além do impacto sobre a mortalidade, geram grande demanda por serviços especializados de urgência/emergência relacionados ao trauma.

Também referentes ao trauma podemos citar as fraturas por fragilidades. De acordo com o presidente do $19^{\circ}$ Congresso Mineiro de Ortopedia ocorrido em 2014, o número de fraturas por fragilidade vem aumentando e estima-se que 30\% das pessoas com mais de 60 anos sofrerão quedas pelo menos uma vez ao ano, e em 5\% delas haverá uma fratura por fragilidade, mais comum no fêmur, vértebra ou punho (Congresso..., 2017). Esses dados seguramente impactam as estruturas de atenção ao trauma de média e alta complexidade. 
Em relação às ações de atenção ao parto, ainda que as taxas de fecundidade tenham se reduzido, permanecem problemas como a mortalidade materna, o aumento das já altas taxas de cesarianas, a prematuridade e as complicações no parto. Esse perfil de assistência está relacionado às políticas de saúde, ao comportamento médico e a interesses do mercado de medicamentos, equipamentos, bem como dos hospitais. Enquanto não se alterar o perfil das altas taxas de cesáreas e as correspondentes taxas de prematuridades e complicações evitáveis, esses fatores continuarão a gerar necessidade de UTI neonatal e de toda a atenção hospitalar envolvida.

Em relação às doenças neuropsiquiátricas, mesmo sem relevância para a questão da mortalidade, com base em evidências científicas, atesta-se uma alta e crescente prevalência na população, o que implica alterações significativas no cotidiano dos indivíduos, das famílias e da sociedade. Embora não tenhamos dados suficientes para inferir sobre as tendências de crescimento desse grupo de doenças, o processo de envelhecimento populacional teve como consequência o aumento dos quadros de demência em quatro vezes, isto é, de 1,8 para 7,0/100.000 habitantes, no período entre 1996 e 2007 (Oliveira \& Oneill, 2013; Barreto, 2013, Luna \& Silva, 2013).

Enfim, o objetivo de assinalar o quê e onde investir em capacidade instalada em saúde para melhor atender aos problemas de saúde da população brasileira nos próximos vinte anos requer uma capacidade do Estado de operacionalização das estratégias de expansão e reorganização do parque tecnológico do setor Saúde, de modo a superar os problemas advindos da insuficiência de recursos humanos, da dualidade público-privada, da transição demográfica e das alterações do perfil epidemiológico da população brasileira, que não se resolvem exclusivamente no setor Saúde.

Esse nó crítico direciona necessariamente para uma articulação com soluções intersetoriais. Quaisquer que sejam nossos projetos de investimento no setor Saúde, em grande parte dos casos estarão implicadas ações tais como construir ou adequar espaços para atender as demandas tecnológicas, demográficas, ou epidemiológicas da população brasileira.

\section{Metodologia}

O estudo foi realizado em duas etapas complementares: revisão bibliográfica e análise dos dados sobre recursos físicos.

\section{Revisão bibliográfica}

Tendo como objetivo descrever a situação atual e identificar os principais problemas e recursos explorados em outras análises sobre a rede assistencial, realizou-se um levantamento de publicações de natureza variada sobre o tema. Pesquisaram-se estudos existentes sobre evolução, tendências e projeções nas áreas de sociodemografia e economia, políticas públicas e situação epidemiológica no Brasil. Diversos capítulos do livro A Saúde no Brasil em 2030: diretrizes para a prospecção estratégica do sistema de saúde brasileiro contribuíram para nortear essa seleção. Também se empreenderam revisão bibliográfica e levantamento de publicações na mídia (jornais e revistas).

Na revisão bibliográfica foram consultadas as bases de dados de artigos científicos Medline, Lilacs e Google e selecionados estudos que tinham como objetivo analisar a oferta de serviços e que 
utilizaram dados da Pesquisa Assistência Médico-Sanitária (AMS) do Instituto Brasileiro de Geografia e Estatística (IBGE) ou do CNES com análises próprias e não apenas descrição de outras análises. Aplicaram-se os seguintes termos:

- Medline: Health Services Accessibility (Availability of Health Services, Health Services Availability, Accessibility, Health Services, Access to Health Care, Accessibility of Health Services, Health Services Geographic Accessibility); Health Care Rationing; provision of health service; Brazil e Brazilian (brazil*).

- Lilacs: Serviços de saúde, estatísticas; dados; acesso aos Serviços de Saúde; Brasil, Brasil*; disponibilidade de serviços de saúde, AMS; IBGE.

\section{Análise dos dados sobre recursos físicos}

A seleção dos principais agravos que afetarão a população em 2034 e os correspondentes recursos físicos de saúde para seu enfrentamento foram subsidiados pela revisão bibliográfica. Os achados da revisão foram organizados de maneira que indicassem algumas áreas da saúde que possivelmente serão importantes objetos de atenção para o SUS em 2034. Além disso, buscou-se o alinhamento com as análises de outros textos deste volume. Por fim, foram selecionados: gestação e parto de alto risco, saúde do idoso, trauma, doença renal, doença cardíaca e oncologia.

Além da análise para os grupos selecionados, considerou-se também a necessidade de se observarem recursos físicos estratégicos na organização da assistência à saúde da população. Exploraramse dados relacionados à rede para assistência da população em suas diversas fases de vida: saúde neonatal, saúde infantil, saúde da mulher e obstetrícia, saúde do adulto e do idoso, e as informações que serão apresentadas a seguir excluem aquelas relacionadas a parto e saúde do idoso.

\section{Fonte de dados}

As informações sobre população utilizadas para construir indicadores de disponibilidade foram obtidas na página do Departamento de Informática do SUS (Datasus). Esses dados se referem às estimativas de população para os períodos intercensitários, disponíveis até o ano de 2012 no tabulador Tabnet à época da extração dos dados.

Uma fonte importante de informações sobre recursos físicos de saúde no Brasil é a AMS, realizada pelo IBGE com apoio do Ministério da Saúde. Essa pesquisa tem como objetivo traçar o perfil dos estabelecimentos de saúde públicos e privados, com ou sem internação, instalados no país (IBGE, 2010). Tem sido aplicada como fonte de informações por diversos estudos científicos que abordam temas relativos à rede de atenção à saúde. Diante de sua metodologia consolidada, espera-se que os resultados obtidos pela AMS sejam fiéis à realidade da rede instalada no país. Entretanto, sua última edição data de 2009, o que se considerou inadequado para retratar a situação atual dos recursos físicos de saúde. Além disso, dados de estabelecimentos não são disponibilizados individualmente pela AMS, o que impossibilitaria a elaboração de análises com dados cruzados de outras fontes.

Outra importante fonte de dados é o CNES, sob gestão do Ministério da Saúde, que contém informações sobre a estrutura física e funcional dos estabelecimentos de saúde públicos e privados no 
país. Passou em 2003 a ser o sistema de informação oficialmente utilizado pelo SUS para o pagamento dos serviços realizados, substituindo um conjunto de campos sobre estabelecimentos que faziam parte do SIH/SUS e do SIA/SUS (Opas, 2008; Carvalho, 2004). De acordo com os atos normativos que o regem, a validação das informações é de responsabilidade do gestor de saúde local, podendo opcionalmente o preenchimento das fichas de cadastramento ser realizado pelos gestores das unidades de saúde (Brasil, 2000a). No setor Saúde Suplementar, desde julho de 2003, estabeleceu-se a obrigatoriedade de cadastramento no CNES para a celebração de contratos entre operadoras de planos de saúde e prestadores de serviços (ANS, 2003). Desde 2004 tornou-se obrigatório o fornecimento do número CNES de todos os prestadores da rede de serviços próprios ou contratados, vinculados a qualquer plano de saúde cadastrado na ANS, para fins de concessão de autorização de funcionamento das operadoras de planos de saúde (ANS, 2004).

Atualmente os maiores desafios do CNES se relacionam a atualização e validação das características de estabelecimentos informadas, especialmente à manutenção de diversas informações funcionais e referentes a programas específicos, a serem registradas no CNES. Apesar disso, em análise recente, Machado (2014) observou o preenchimento completo e consistente dos campos de dados cadastrais de estabelecimentos com internação entre 2008 e 2010, inclusive na comparação destes campos com os similares coletados pela AMS. Outra pesquisa já havia destacado a importância desse cadastro nacional como base para os sistemas de informação sobre assistência à saúde no Brasil, enfatizando sua aplicação na auditoria de serviços, estruturas físicas e recursos humanos (Nascimento, 2012).

Optou-se por utilizar apenas os dados do CNES, considerando o seu ganho de estabilidade nos últimos anos, a disponibilidade de dados individualizados de estabelecimentos, e também as diferenças conceituais entre AMS e CNES que não possibilitaram a construção de séries históricas agregando dados das duas fontes. Isso impediu a aplicação de metodologias mais robustas para a obtenção de projeções. Assim, no lugar de projeções para os próximos vinte anos, elaborou-se um retrato da situação atual.

Foram utilizados os arquivos de dados disponibilizados publicamente na página de internet do Datasus. ${ }^{2}$ O número do CNES e o código IBGE do município foram aplicados como chaves na vinculação das informações.

\section{Análise dos dados}

Foram identificados os recursos necessários para a execução da assistência à saúde da população nas diversas fases da vida, bem como para atender às condições de saúde selecionadas a partir da revisão realizada. Para isso, foram pesquisados atos normativos e estudos científicos especializados em cada tema. Em seguida, foram analisadas as informações disponibilizadas no CNES, selecionando-se aquelas que mais se aproximassem das questões de interesse, com ênfase nos recursos hospitalares. Os hospitais foram categorizados por porte de leitos totais, considerando políticas e portarias existentes, e por porte de leitos de UTI conforme listado no Quadro 1.

\footnotetext{
${ }^{2}$ Ver $<$ cnes.datasus.gov.br $>$.
} 
Quadro 1 - Dados para análise das estruturas por fases da vida e condições selecionadas

\section{Hospitais por porte (por natureza jurídica)}

1.1 Porte de leitos (total existente, excluindo complementares, psiquiatria, acolhimento noturno e hospital-dia)

- Categoria 1: até 12 leitos (Política de Unidades Mistas)

- Categoria 2: de 13 a 49 leitos (hospital de pequeno porte - portaria n. 1.044/2004)

- Categoria 3: de 50 a 79 leitos

- Categoria 4: de 80 a 99 leitos

- Categoria 5: de 100 a 149 leitos

- Categoria 6: de 150 a 199 leitos

- Categoria 7: de 200 a 299 leitos

- Categoria 8: 300 ou mais leitos

1.2 Porte de leitos de UTI (adulto, pediátrico, neonatal)

- Categoria 1: até 5 leitos

- Categoria 2: de 6 a 10 leitos

- Categoria 3: 11 ou mais leitos

\section{Condições selecionadas}

Trauma de média complexidade

Trauma de alta complexidade

Doença renal

Doença cardíaca

Por meio da base cadastral do CNES buscou-se descrever os estabelecimentos existentes segundo localização geográfica (com ênfase nos municípios) e segundo características selecionadas: natureza jurídica, tipo de atendimento prestado, tipo de estabelecimento. Essas variáveis foram recategorizadas, tendo como objetivo agregar dados muito detalhados e selecionar apenas aqueles que se enquadrassem no escopo deste estudo. Observaram-se os leitos existentes nas unidades segundo tipos e subtipos, excluindo-se da análise os leitos de psiquiatria, acolhimento noturno e hospital-dia. Averiguou-se ainda a disponibilidade dos leitos para o SUS, classificando-os em SUS e Não SUS. Foram selecionados, para elaboração dos mapas, os equipamentos de interesse em uso, não sendo considerados os existentes e fora de uso. Todas as categorias, filtros e agregações utilizadas estão descritas no Quadro 2. Por exemplo, para hospital geral ou especializado foram considerados os conteúdos relativos aos campos 5 e 7, como demonstrado no quadro a seguir. 
Quadro 2 - Categorias, campos e códigos do CNES utilizados nos filtros e referências para a seleção de recursos a serem analisados

\begin{tabular}{|c|c|c|}
\hline $\begin{array}{l}\text { Informação } \\
\text { analisada }\end{array}$ & Recursos físicos de saúde analisados e códigos dos filtros aplicados & Referências \\
\hline $\begin{array}{l}\text { Características } \\
\text { de hospitais }\end{array}$ & $\begin{array}{l}\text { • Natureza jurídica (campo "natureza") } \\
\text { Incluídos agregados: } \\
\text { 1,2,3,4,5,6: público } \\
\text { 11: privado sem fins lucrativos } \\
\text { 7,8,9,10,12: privado com fins lucrativos } \\
\text { - Tipo de atendimento prestado (campo "atendimento_prestado") } \\
\text { Incluídos: } \\
\text { 1- internação; } \\
\text { 2- ambulatorial; } \\
\text { 3- serviços de apoio diagnóstico e terapêutico (SADT); } \\
\text { 4- urgência. } \\
\text { - Tipo de estabelecimento (campo "tipo_unidade") } \\
\text { Incluídos agregados: } \\
\text { 1,2: centro ou posto de saúde } \\
\text { 4,36: policlínica, clínica ou ambulatório especializado } \\
\text { 5,7: hospital geral ou especializado } \\
\text { 20,21: pronto-socorro geral, pronto-socorro especializado } \\
\text { 39: unidade de SADT }\end{array}$ & \\
\hline $\begin{array}{l}\text { Características } \\
\text { de leitos }\end{array}$ & $\begin{array}{l}\text { - Tipo de leito (campo "tp_leito") } \\
\text { Incluídos: } \\
\text { 1- cirúrgicos; } \\
\text { 2- clínicos; } \\
\text { 3- obstétricos; } \\
\text { 4- pediátricos; } \\
\text { 5- outras especialidades; } \\
\text { 7- complementar. } \\
\text { Excluídos: } \\
\text { 6- hospital-dia. } \\
\text { - Subtipo de leito (campo "co_leito") } \\
\text { Incluídos agregados: } \\
\text { 74,75,76: UTI adulta } \\
\text { 77,78,79: UTI pediátrica } \\
\text { 80,81,82: UTI neonatal } \\
\text { Excluídos: } \\
\text { 84: acolhimento noturno } \\
\text { 47: psiquiatria } \\
\text { Incluídos todos os demais } \\
\text { - SUS e Não SUS (campos “qt_exist" e "qt_SUS") } \\
\text { SUS = qt_SUS } \\
\text { Não SUS = qt_exist - qt_SUS }\end{array}$ & $\begin{array}{l}\text { Manual CNES } 2008 \text { e } \\
\text { Manual CNES } 2006 \text {. } \\
\text { Disponível em: <cnes. } \\
\text { datasus.gov.br>. } \\
\text { Acesso em: } 30 \text { jun. } \\
2014\end{array}$ \\
\hline Equipamentos & $\begin{array}{l}\text { - Equipamentos } \\
\text { Incluídos agregados: } \\
\text { 2,3,17: mamografia } \\
\text { 4,5,6: raios X } \\
\text { 10: raios X para hemodinâmica } \\
\text { 11: tomografia computadorizada } \\
\text { 12: ressonância magnética } \\
\text { 13,14,15: ultrassonografia } \\
\text { 76: circulação extracorpórea } \\
\text { 77: hemodiálise } \\
\text { bomba de cobalto (arquivos de dados complementares) }\end{array}$ & \\
\hline
\end{tabular}


Quadro 2 - Categorias, campos e códigos do CNES utilizados nos filtros e referências para a seleção de recursos a serem analisados (cont.)

\begin{tabular}{|c|c|c|}
\hline & $\begin{array}{l}\text { - Selecionaram-se estabelecimentos com atendimento hospitalar. A presença } \\
\text { de cinco itens estruturais foi observada em cada um deles, atribuindo-se uma } \\
\text { pontuação de } 0 \text { a } 5 \text { de acordo com o número de estruturas existentes. } \\
\text { - Itens de estrutura analisados: }\end{array}$ & $\begin{array}{l}\text { Política Nacional de } \\
\text { Atenção às Urgências } \\
\text { (2006); } \\
\text { Portaria GM n. } 2.048 \\
\text { de } 5 \text { de novembro de } \\
\text { 2002; }\end{array}$ \\
\hline $\begin{array}{l}\text { Trauma - média } \\
\text { complexidade }\end{array}$ & $\begin{array}{l}\text { - Leitos: UTI (co_leito = 74,75,76), hospitais com mais de } 100 \text { leitos. } \\
\text { - Equipamentos: tomografia computadorizada (11). } \\
\text { - Serviços: assistência de alta complexidade em neurocirurgia (105- serviço } \\
\text { de assistência de alta complexidade em neurocirurgia - exige neurocirurgia e } \\
\text { traumatologia), hemoterapia (serviço 128). }\end{array}$ & $\begin{array}{l}\text { "Abordagem } \\
\text { ao Paciente } \\
\text { Politraumatizado: } \\
\text { protocolos clínicos" } \\
\text { (Secretaria de Estado } \\
\text { de Saúde de Minas } \\
\text { Gerais, 2011); e } \\
\text { Portaria n. 1.366, de } 8 \\
\text { de julho de } 2013 \text {. }\end{array}$ \\
\hline $\begin{array}{l}\text { Trauma - alta } \\
\text { complexidade }\end{array}$ & $\begin{array}{l}\text { - Selecionaram-se estabelecimentos com atendimento hospitalar. A presença } \\
\text { de oito itens estruturais foi observada em cada um deles, atribuindo-se uma } \\
\text { pontuação de } 0 \text { a } 8 \text { de acordo com o número de estruturas existentes. } \\
\text { - Itens de estrutura analisados: } \\
\text { - Leitos: UTI (co_leito=74,75,76), hospitais com mais de } 100 \text { leitos. } \\
\text { - Equipamentos: tomografia computadorizada (11), ressonância magnética (12). } \\
\text { - Serviços: assistência de alta complexidade em neurocirurgia (105- serviço } \\
\text { de assistência de alta complexidade em neurocirurgia - exige neurocirurgia e } \\
\text { traumatologia), hemoterapia (serviço 128), radiologia intervencionista (serviço } \\
\text { 121, classe 006), reabilitação (serviço 135). }\end{array}$ & $\begin{array}{l}\text { Política Nacional de } \\
\text { Atenção às Urgências } \\
\text { (2006); } \\
\text { Portaria GM n. } 2.048 \\
\text { de } 5 \text { de novembro de } \\
2002 \text {; } \\
\text { "Abordagem } \\
\text { ao Paciente } \\
\text { Politraumatizado: } \\
\text { protocolos clínicos" } \\
\text { (SES/MG, 2011); e } \\
\text { Portaria n.1.366, de } 8 \\
\text { de julho de 2013. }\end{array}$ \\
\hline Doença renal & $\begin{array}{l}\text { - Selecionaram-se estabelecimentos com ou sem atendimento hospitalar. Foram } \\
\text { analisados os estabelecimentos com equipamento de hemodiálise, segundo } \\
\text { habilitação em nefrologia e para transplante de rim. } \\
\text { - Itens de estrutura analisados: } \\
\text { - Equipamento de hemodiálise (77) } \\
\text { - Habilitação como "Unidade de Assistência de Alta Complexidade em Nefrologia } \\
\text { (1501 Serviço de Nefrologia)" ou Habilitação como "Centro de Referência de Alta } \\
\text { Complexidade em Nefrologia" (1502) } \\
\text { - Habilitação para transplante de rim (2408) }\end{array}$ & $\begin{array}{l}\text { Portaria n. } 1168 / \mathrm{GM} \\
\text { de } 15 \text { de junho de } \\
2004 \text {; } \\
\text { Portaria SAS/MS n. } \\
211 \text {, de } 15 \text { de junho } \\
\text { de } 2004 \text {; } \\
\text { e Portaria SE/SAS n. } \\
55 \text { de } 29 \text { de agosto de } \\
2001 .\end{array}$ \\
\hline Doença cardíaca & $\begin{array}{l}\text { - Selecionaram-se estabelecimentos com atendimento hospitalar, habilitados para } \\
\text { a realização de cirurgia cardíaca em adulto ou pediatria. A presença de UTI e } \\
\text { circulação extracorpórea foi observada para cada estabelecimento. } \\
\text { - Itens de estrutura analisados: } \\
\text { - Serviços: cirurgia cardiovascular adulto (serviço 116, classe 002) ou cirurgia } \\
\text { cardiovascular pediátrica (serviço } 116 \text {, classe } 003 \text { ). } \\
\text { - Leitos: UTI adulta (co_leito=74,75,76) ou UTI pediátrica (co_ } \\
\text { leito=77,78,79,80,81,82) } \\
\text { - Equipamentos: circulação extracorpórea (76) }\end{array}$ & $\begin{array}{l}\text { Portaria n. } 210 \text { de } 15 \text { de } \\
\text { junho de } 2004\end{array}$ \\
\hline
\end{tabular}


Para as análises de estruturas envolvendo leitos para internação, construiu-se uma base de dados com todos os estabelecimentos cujo campo "tipo de atendimento prestado" no CNES estava definido como "com internação". Entre esses, foram excluídos os estabelecimentos sem leitos. Nessa base, foram incluídas todas as variáveis relativas a hospitais e leitos. Também foram construídas bases específicas para as análises de equipamentos, serviços e condições de saúde selecionadas.

\section{Resultados da Etapa de Revisão Bibliográfica}

A oferta de serviços no país é amplamente desigual, concentrando-se nas regiões Sudeste e Sul, principalmente para serviços de média e alta complexidade e para a disponibilização de mão de obra qualificada. Relata-se, nos estudos, a existência de grandes áreas com deficiências absolutas em equipamentos, instalações físicas e recursos humanos, mesmo para unidades de saúde com baixos níveis de complexidade (Rodrigues, Amaral \& Simões, 2007; Cazelli et al., 2002).

Dados de 2010 indicavam que as unidades de atenção básica e as de emergência eram, em geral, públicas, enquanto os hospitais, ambulatórios e serviços de apoio diagnóstico e terapêutico (SADT) eram, em sua maioria, privados, mas com uma parcela importante desses recursos contratados pelo SUS (Paim et al., 2011). Ressalta-se um crescimento da estrutura de serviços ambulatoriais públicos em todo o país, embora permaneçam as desigualdades regionais e a baixa capacidade resolutiva dessas unidades. Tal crescimento esteve associado ao intenso processo de descentralização que destinou maior responsabilidade aos municípios na gestão dos serviços de saúde nos últimos vinte anos (Paim et al., 2011; Costa \& Costa, 2002; Viacava \& Bahia, 2002; Mendes et al., 2012), junto com a implantação do Programa Saúde da Família, atual Estratégia Saúde da Família (ESF).

Há características importantes a considerar nas análises dos serviços ambulatoriais privados, como a feita por Viacava e Bahia (2002), limitadas no que se refere aos atendimentos vinculados às operadoras de planos privados de saúde, uma vez que os consultórios particulares, que representam o principal recurso da assistência ambulatorial das operadoras de planos privados, não estavam incluídos na pesquisa da AMS 92/99 e apenas nos últimos anos foram incorporados ao CNES.

A maior parte da oferta de leitos hospitalares e de unidades prestadoras de SADT era de propriedade privada. Contudo, a maioria desses leitos privados mantinha contrato pelo SUS (Santos, Ugá \& Porto, 2008). Identifica-se, nos últimos anos, a redução na oferta de leitos hospitalares, o que relativiza o peso dos hospitais no modelo assistencial brasileiro. Tal redução ocorreu de forma desigual entre os serviços privados e os públicos. Além disso, em 2004, apenas 2,2\% dos leitos nacionais eram de UTI e 22,8\% estavam em hospitais com menos de cinquenta leitos, menos efetivos e eficientes que os hospitais maiores (Mendes et al., 2012; Paim et al., 2011; Vecina Neto \& Malik, 2007; La Forgia \& Couttolenc, 2009).

Mesmo com a proeminência do SUS e a legitimidade constitucional do Estado brasileiro para garantir que o interesse público viesse a ser orientador do sistema de saúde, na prática o sistema de saúde brasileiro é constituído pelos setores público e privado, e as interações entre eles formam uma rede complexa de prestadores e compradores de serviços que competem entre si, gerando resultados negativos para a equidade e o acesso aos serviços de saúde, bem como para as condições de saúde 
da população (Paim et al., 2011; Santos, Ugá \& Porto, 2008). Nesse cenário está também uma parcela dos usuários dos serviços financiados pelo SUS e outra de planos privados, com maior poder aquisitivo e mais amplo acesso, e que ainda podem usar tanto os serviços financiados pelos planos de saúde em prestadores privados, como os financiados pelo SUS, seja em prestadores privados ou públicos (Santos, Santos \& Borges, 2013).

Tomando por base a análise da produção de serviços de saúde no período de 1999 a 2009, Mendes e colaboradores (2012) identificaram redução no número de internações pagas pelo SUS, ampliação da assistência ambulatorial, crescimento da assistência de alta complexidade ambulatorial e hospitalar e distribuição dos leitos e das internações nas especialidades não adequada às necessidades da população. Segundo os autores, o processo parece não levar em consideração as transformações exigidas pelo momento de transição demográfica, social e epidemiológica no Brasil (Mendes et al., 2012).

\section{Evolução da oferta da estrutura de serviços de saúde no Brasil de 1900 a 2000}

A trajetória da expansão da estrutura de serviços físicos de saúde ao longo do século XX foi analisada em Pessôa (2005) por meio dos dados de 2002 do CNES. Nos Gráficos 1, 2 e 3 são apresentadas as evoluções do número de unidades de saúde (SADT, unidades com internação e unidades sem internação), considerando a data de início de atividades.

No Gráfico 1, demonstra-se ligeiro decréscimo na curva de expansão das unidades hospitalares do SUS a partir de 1970, em detrimento do crescimento do número total de unidades, sugerindo que o setor privado continuou investindo na expansão de suas unidades hospitalares, embora em menor ritmo que nas décadas passadas.

Gráfico 1 - Evolução do número de unidades de saúde com internação, segundo década de início de atividade. Brasil - século XVI a XX

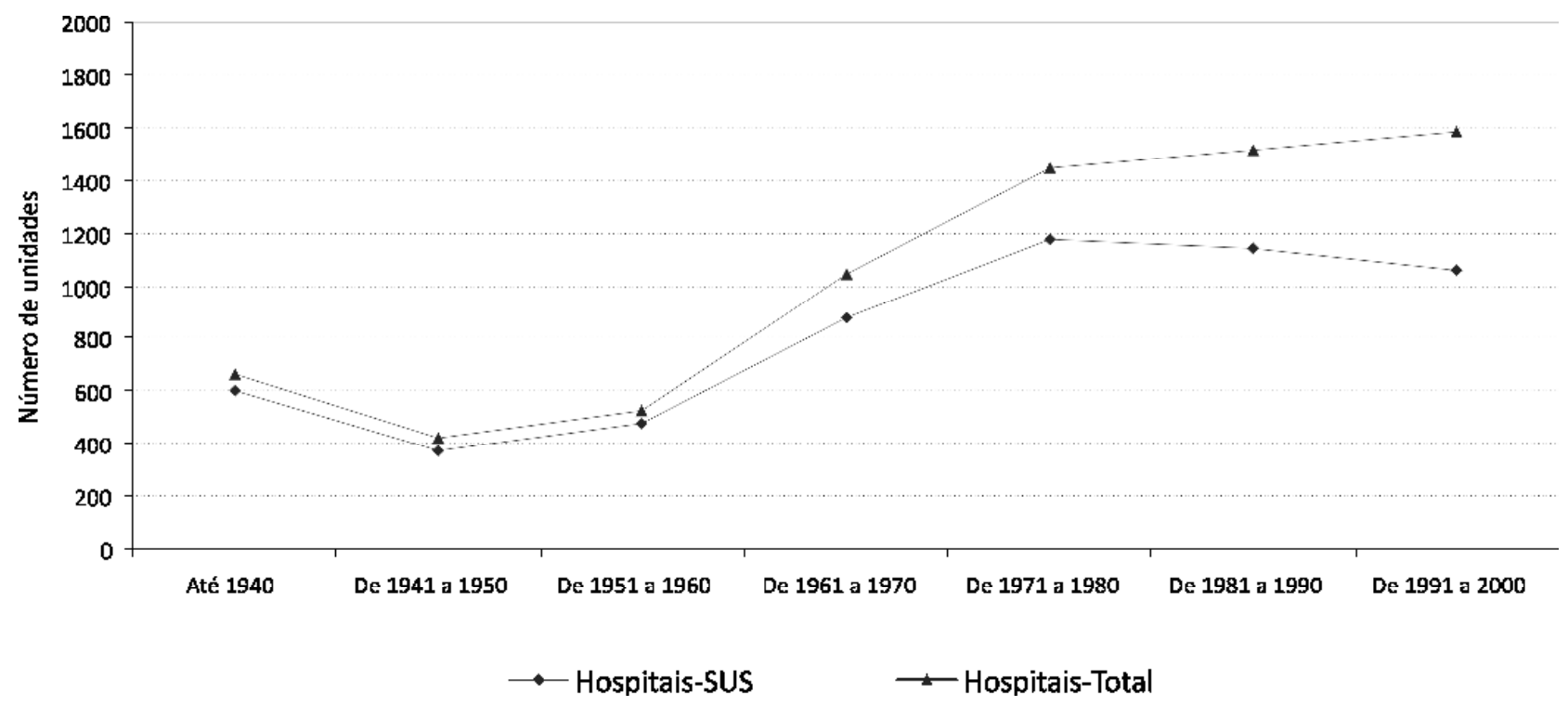

Fonte: Pessôa (2005). 
Por sua vez, no Gráfico 2, relativo à expansão das unidades sem internação, além de delinear-se a expressiva expansão das unidades SUS em contrapartida às da iniciativa privada, evidencia-se o crescimento desse tipo de unidade, sugerindo ainda uma tendência de continuidade.

Gráfico 2 - Evolução do número de unidades de saúde sem internação, segundo década de início de atividade. Brasil - século XVI a XX

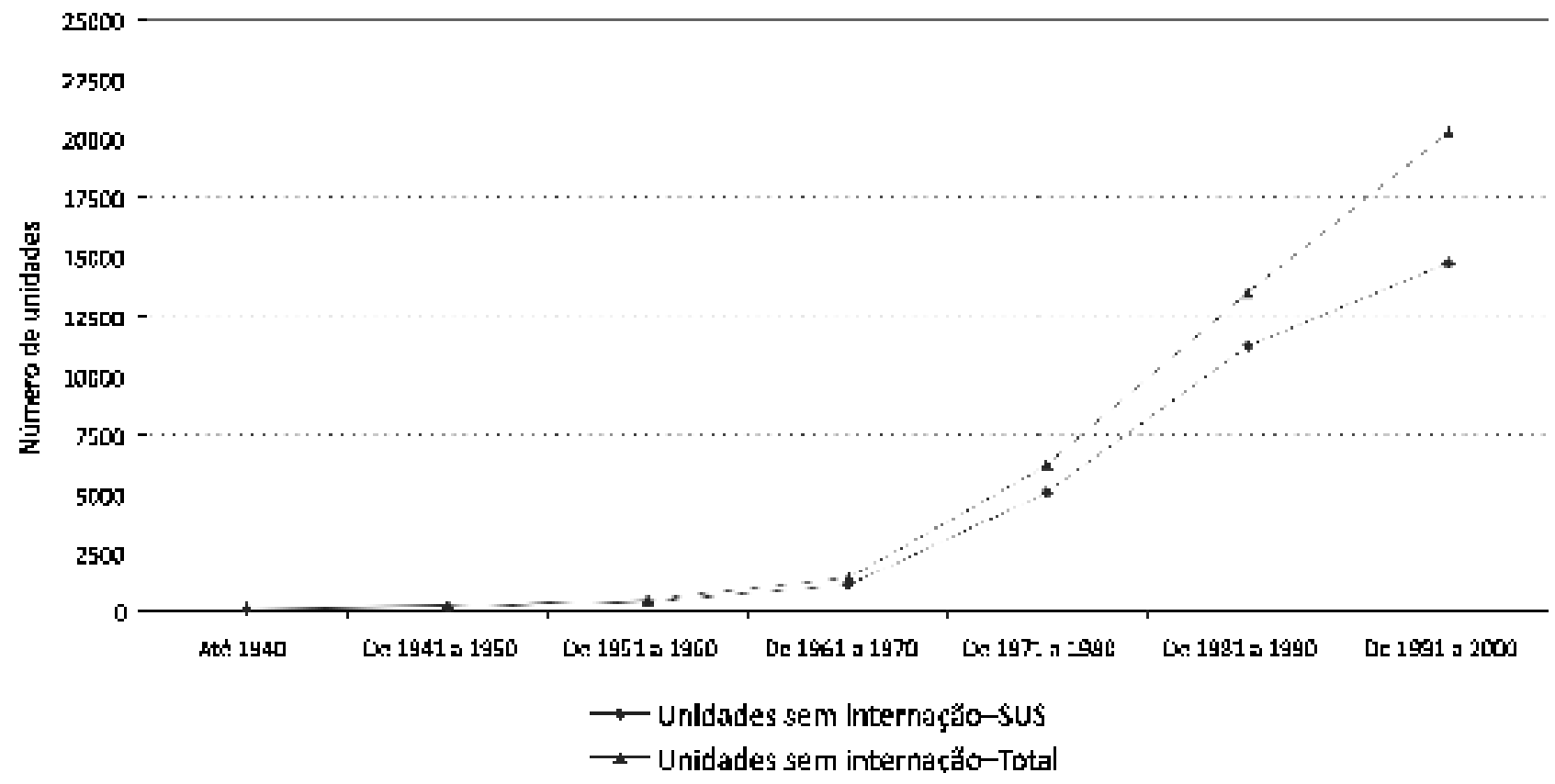

Fonte: Pessôa (2005).

No Gráfico 3, expressa-se a desigualdade do crescimento entre a estrutura de serviços SUS e o setor privado no que diz respeito aos SADT, um dos atuais pontos de estrangulamento da atenção à saúde pela estrutura de serviços SUS, tanto em relação à média como à alta complexidade. Do total de 13.484 unidades desse tipo, apenas 5.218 oferecem serviços ao SUS. 
Gráfico 3 - Evolução do número de unidades de saúde de SADT, segundo década de início de atividade. Brasil - século XVI a XX

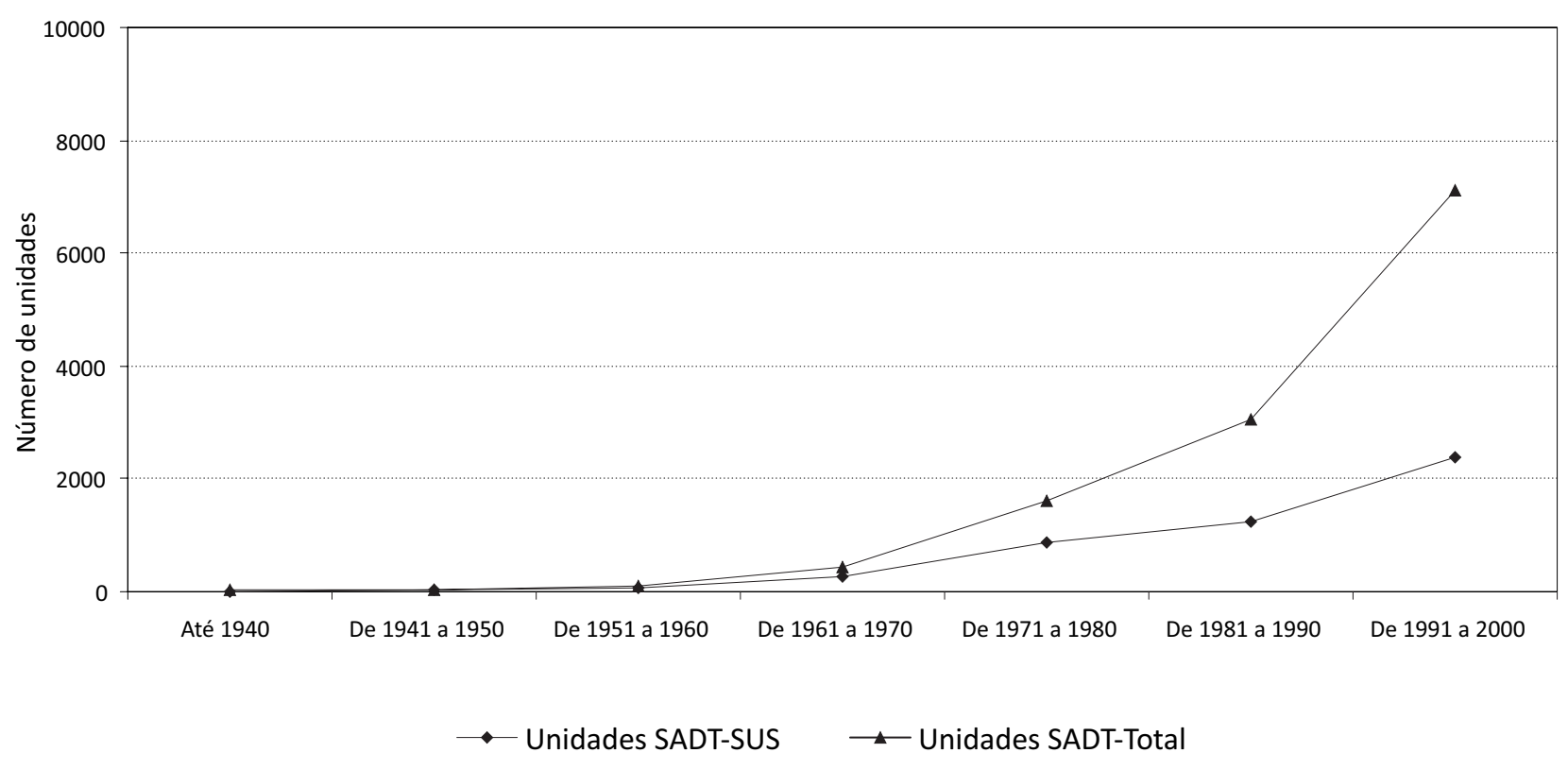

Fonte: Pessôa (2005).

As transformações ocorridas no século XX podem ser organizadas em períodos (Pessôa, 2005), que se destacam a seguir.

Entre 1901 e 1940: a virada do século XIX foi marcada por inúmeros avanços, em todos os campos do conhecimento, com a incorporação de novos saberes e técnicas. As transformações nos hospitais são intensas e profundas, tendo-se dado um salto para a modernidade. Nesse período prevalecem ainda as instituições filantrópicas e, na década de 1930, inicia-se a construção de sanatórios de tuberculose pelas instâncias estaduais, que configuram novo componente importante na oferta de serviços para aquele problema de saúde.

Entre 1941 e 1970: período marcado pela Campanha da Borracha, na Amazônia, determinante para a criação do Serviço Especial de Saúde Pública (Sesp), posteriormente denominada Fundação Serviços de Saúde Pública (FSESP), em 1942. A FSESP atuou como financiadora da expansão da estrutura de serviços de Atenção Primária à Saúde (APS), construindo postos e centros de saúde e unidades mistas no interior. O Ministério da Saúde, criado em 1953, financiou a construção de sanatórios de tuberculose em todo o país. É nesse contexto que tem início o delineamento mais expressivo da expansão da estrutura pública de saúde, sobretudo a de natureza municipal.

Entre 1971 e 1990: este período está sob a égide da incorporação de novas tecnologias e da crise de financiamento no setor Saúde, iniciada no fim da década de 1970, que interfere fortemente na capacidade de o Estado custear as unidades existentes e traz à tona a crescente necessidade de racionalização na expansão da estrutura pública de serviços de saúde. 
Nesse contexto, impôs-se aos financiadores da expansão a necessidade de compartilhar os sistemas de engenharia, reforçando as teses de organização do sistema já apresentadas no Reino Unido no Relatório Dawson, de 1920 (Kuschnir \& Chorny, 2010), dando origem, aqui no Brasil, a partir da década de 1970, aos primeiros movimentos de regionalização, hierarquização e descentralização de serviços, de modo a imprimir ao sistema de saúde a noção de territórios de saúde.

Nesse período a noção de estrutura/rede de saúde passou a permear os investimentos para a expansão e transformação das unidades de saúde. Três grandes projetos de investimentos subsidiaram essa transformação: o Programa de Interiorização das Ações de Saúde e Saneamento (Piass), o Fundo de Apoio ao Desenvolvimento Social da Caixa Econômica, vinculado ao Plano de Localização de Unidades de Saúde (Plus) e ao Projeto Nordeste. No âmbito da formação de capital humano para a saúde, destacam-se o Movimento Larga Escala e o Programa de Preparação Estratégica do Pessoal de Saúde (PPREPS). O período foi marcado, ainda, pelas Ações Integradas de Saúde (AIS) que, na década de 1980, também impulsionaram o crescimento de unidades básicas de saúde.

A partir da década de 1980, em relação à incorporação na área de diagnóstico por imagem, por exemplo, estabeleceu-se um grande problema na operacionalização das políticas quando os hospitais da estrutura física do SUS, alguns do início do século XX, passaram a ter que acomodar tomógrafos, ressonâncias magnéticas, angiografia e ultrassonografia, em espaços previamente inexistentes, uma vez que na época de concepção da maioria dessas unidades se considerava apenas a existência de aparelhos de raios $\mathrm{X}$ simples. A mudança tecnológica no corpo físico dos aparelhos foi tão grande que na década de 1980 um aparelho de ressonância pesava trinta toneladas, ao passo que hoje pesa dez toneladas, ou seja, em vinte anos perdeu vinte toneladas.

Entre 1990 e 2000: o período foi marcado pelos investimentos do projeto Reforço à Reorganização do Sistema Único de Saúde (Projeto ReforSUS) e do Programa Saúde da Família (PSF). Desenvolveram-se, também, o Projeto de Profissionalização de Trabalhadores da Área de Enfermagem (Profae), voltado para a formação e a capacitação de trabalhadores da saúde, o Projeto de Vigilância em Saúde no SUS (VigiSUS), além de outros, de âmbito estadual ou municipal. Foram instituídas as Normas Operacionais 93 e 96, ambas de caráter municipalista, reforçando a importância da gestão municipal na organização de sua estrutura de serviços.

\section{Resultados da Etapa de Análise dos Dados sobre Recursos Físicos: a oferta da estrutura de serviços de saúde no Brasil em 2013}

Em dezembro de 2013 havia mais de 44 mil postos e centros de saúde, cerca de 41 mil policlínicas e clínicas especializadas, 20 mil estabelecimentos de SADT, 6,3 mil hospitais e 1 mil prontos-socorros.

A distribuição dos estabelecimentos difere nas regiões do país, especialmente para aqueles relacionados ao cuidado ambulatorial. No Sul e Sudeste, os consultórios eram mais de $60 \%$ dos estabelecimentos registrados, enquanto no Norte e Nordeste eram pouco mais de $32 \%$. Já os postos e centros de saúde que totalizavam 36\% dos estabelecimentos no Norte e Nordeste, variavam entre 12\%, 14\% e 15\% nas regiões Sudeste, Sul e Centro-Oeste respectivamente (Gráfico 4). 
Gráfico 4 - Número de estabelecimentos de saúde segundo tipo e grandes regiões. Brasil - 2013

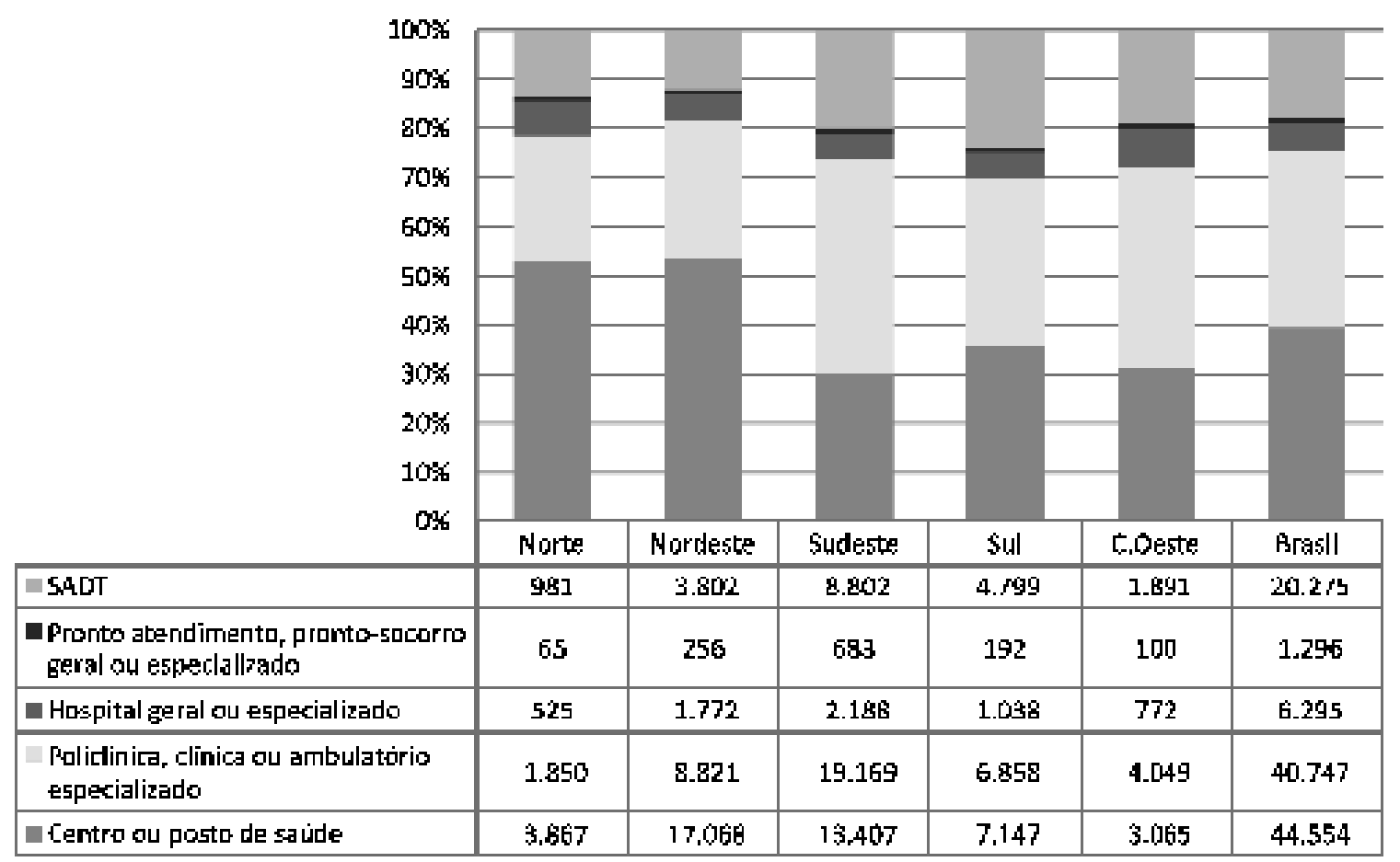

Fonte: elaborado pelas autoras, com base em dados do CNES referentes ao ano de 2013 (Brasil, 2014).

Observa-se que os centros de saúde, postos de saúde, centros de atenção psicossocial (Caps), prontos-socorros e unidades de pronto atendimento eram majoritariamente públicos. Já os consultórios, clínicas especializadas, ambulatórios especializados, policlínicas e SADT eram majoritariamente privados com fins lucrativos. Os hospitais gerais e especializados de natureza pública e os de natureza privada com fins lucrativos existiam em proporções semelhantes. Os estabelecimentos privados sem fins lucrativos eram em sua maioria hospitais gerais e clínicas especializadas. Nas regiões Norte e Nordeste, havia proporcionalmente menos estabelecimentos privados de saúde que nas demais regiões (Tabela 1). 
Tabela 1 - Estabelecimentos segundo natureza jurídica e tipo. Brasil e Regiões - 2013

\begin{tabular}{|c|c|c|c|c|c|c|}
\hline Região & $\begin{array}{l}\text { Natureza } \\
\text { Jurídica }\end{array}$ & $\begin{array}{c}\text { Centro ou } \\
\text { posto de saúde }\end{array}$ & $\begin{array}{l}\text { Policlínica, } \\
\text { clínica ou } \\
\text { ambulatório } \\
\text { especializado }\end{array}$ & $\begin{array}{c}\text { Hospital } \\
\text { geral ou } \\
\text { especializado }\end{array}$ & $\begin{array}{c}\text { Pronto } \\
\text { atendimento, } \\
\text { pronto-socorro } \\
\text { geral ou } \\
\text { especializado }\end{array}$ & SADT \\
\hline \multirow{3}{*}{ Norte } & Público & 3.834 & 277 & 284 & 56 & 113 \\
\hline & $\begin{array}{l}\text { Priv. sem fins } \\
\text { lucrativos }\end{array}$ & 8 & 42 & 32 & - & 10 \\
\hline & $\begin{array}{l}\text { Priv. com fins } \\
\text { lucrativos }\end{array}$ & 25 & 1.531 & 209 & 9 & 858 \\
\hline \multirow{3}{*}{ Nordeste } & Público & 16.755 & 1.450 & 918 & 180 & 485 \\
\hline & $\begin{array}{l}\text { Priv. sem fins } \\
\text { lucrativos }\end{array}$ & 36 & 223 & 263 & 5 & 17 \\
\hline & $\begin{array}{l}\text { Priv. com fins } \\
\text { lucrativos }\end{array}$ & 277 & 7.148 & 591 & 71 & 3.300 \\
\hline \multirow{3}{*}{ Sudeste } & Público & 13.239 & 2.450 & 509 & 579 & 477 \\
\hline & $\begin{array}{l}\text { Priv. sem fins } \\
\text { lucrativos }\end{array}$ & 40 & 705 & 837 & 14 & 141 \\
\hline & $\begin{array}{l}\text { Priv. com fins } \\
\text { lucrativos }\end{array}$ & 128 & 16.014 & 842 & 90 & 8.184 \\
\hline \multirow{3}{*}{ Sul } & Público & 7.033 & 653 & 249 & 147 & 155 \\
\hline & $\begin{array}{l}\text { Priv. sem fins } \\
\text { lucrativos }\end{array}$ & 32 & 576 & 467 & 8 & 76 \\
\hline & $\begin{array}{l}\text { Priv. com fins } \\
\text { lucrativos }\end{array}$ & 82 & 5.629 & 322 & 37 & 4.568 \\
\hline \multirow{3}{*}{$\begin{array}{l}\text { Centro- } \\
\text { Oeste }\end{array}$} & Público & 3.034 & 440 & 289 & 79 & 144 \\
\hline & $\begin{array}{l}\text { Priv. sem fins } \\
\text { lucrativos }\end{array}$ & - & 74 & 95 & - & 15 \\
\hline & $\begin{array}{l}\text { Priv. com fins } \\
\text { lucrativos }\end{array}$ & 25 & 3.535 & 388 & 21 & 1.732 \\
\hline \multirow{3}{*}{ Brasil } & Público & 43.895 & 5.270 & 2.249 & 1.041 & 1.374 \\
\hline & $\begin{array}{l}\text { Priv. sem fins } \\
\text { lucrativos }\end{array}$ & 116 & 1.620 & 1.694 & 27 & 259 \\
\hline & $\begin{array}{l}\text { Priv. com fins } \\
\text { lucrativos }\end{array}$ & 537 & 33.857 & 2.352 & 228 & 18.642 \\
\hline
\end{tabular}

Fonte: elaborado pelos autores, com base em dados do CNES referentes ao ano de 2013 (Brasil, 2014). 


\section{Estabelecimentos de saúde por porte de leitos}

O Brasil tinha, em 2013, aproximadamente 6.500 unidades de saúde (US) com leitos disponíveis para internação, incluindo os leitos de UTI e excluindo aqueles só com leitos de psiquiatria, leitos-dia e leito de acolhimento noturno.

A análise do Gráfico 5 e Tabela 2 indica que aproximadamente 80\% dos estabelecimentos que oferecem internação contavam com menos de cem leitos.

Além disso, entre os municípios que apresentavam unidades de saúde com internação, 87\% dispunham apenas de unidades com menos de cem leitos. Apenas $2 \%$ dos estabelecimentos tinham mais de 300 leitos, distribuídos em apenas $2 \%$ dos municípios que ofereciam internação.

Gráfico 5 - Distribuição de estabelecimentos com internação por número de leitos. Brasil - 2013

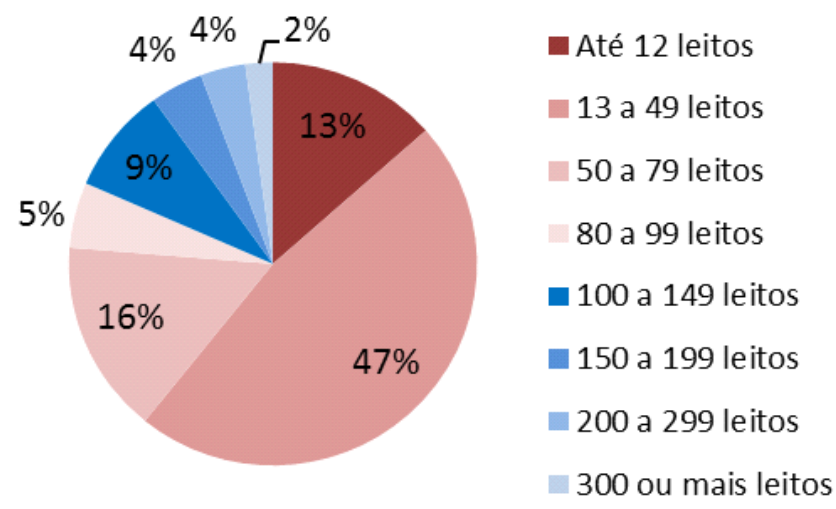

Fonte: elaborado pelos autores, com base em dados do CNES referentes ao ano de 2013 (Brasil, 2014).

Tabela 2 - Número e percentual de estabelecimentos e de municípios segundo número de leitos disponibilizados. Brasil - 2013

\begin{tabular}{|l|c|r|r|r|}
\hline Número de leitos & $\begin{array}{c}\text { N. de } \\
\text { estabelecimentos }\end{array}$ & \multicolumn{1}{c|}{$\%$} & N. de municípios & $\%$ \\
\hline Até 12 leitos & 896 & 13,5 & 304 & 8,6 \\
\hline 13 a 49 leitos & 3.141 & 47,3 & 2.062 & 58,6 \\
\hline 50 a 79 leitos & 1.029 & 15,5 & 544 & 15,5 \\
\hline 80 a 99 leitos & 349 & 5,3 & 140 & 4,0 \\
\hline 100 a 149 leitos & 567 & 8,5 & 229 & 6,5 \\
\hline 150 a 199 leitos & 278 & 4,2 & 103 & 2,9 \\
\hline 200 a 299 leitos & 237 & 3,6 & 82 & 2,3 \\
\hline 300 ou mais leitos & 144 & 2,2 & 57 & 1,6 \\
\hline Total & 6.641 & 100,0 & 3.521 & 100,0 \\
\hline
\end{tabular}

Fonte: elaborado pelas autoras, com base em dados do CNES referentes ao ano de 2013 (Brasil, 2014). 
As unidades de saúde (US) com internação estavam distribuídas em aproximadamente 3.500 municípios. Observa-se, na região central do país, um vazio importante na oferta de leitos de internação. A Figura 6 permite observar a distribuição espacial das unidades de saúde segundo número de leitos.

A cor branca representa os municípios que não dispunham de estabelecimentos com internação. Na Figura 1A utilizou-se a maior classe disponível. Nos demais (B, C, D e E) para uma melhor visualização, as unidades de saúde foram agrupadas em: B) US com até 49 leitos; C) US com 50-99 leitos; D) US com 100-299 leitos; e E) US com 300 ou mais leitos. É possível observar que a área assinalada no mapa concentra os estabelecimentos de maior porte, o que pode ser explicado pela característica desses locais de concentração do emprego, indústria, nível de renda e escolaridade, sistema viário etc.

Figura 1 - Distribuição dos estabelecimentos com internação segundo número de leitos por município. Brasil - 2013

A. Distribuição segundo maior classe disponível

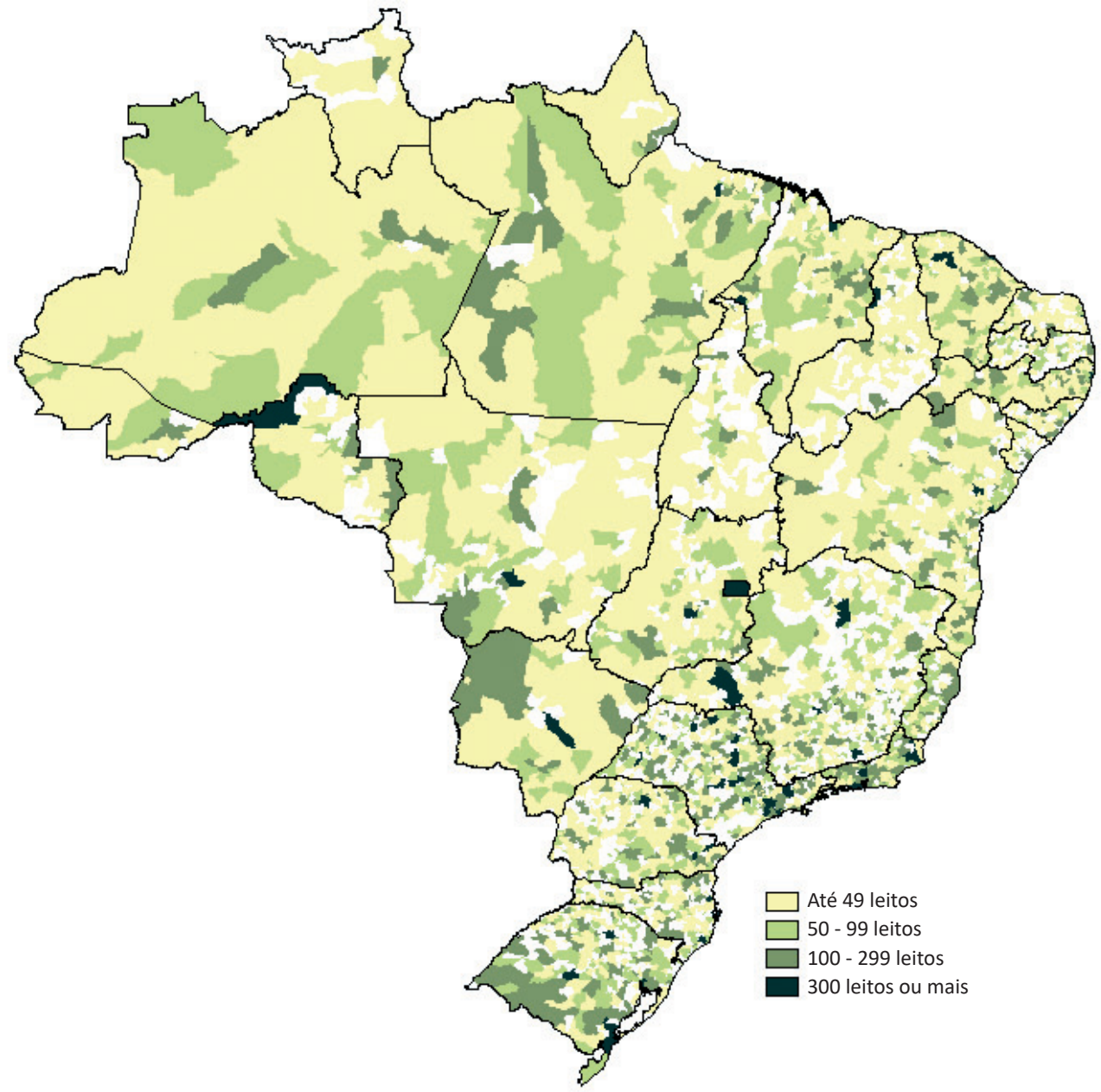


B. Até 49 leitos

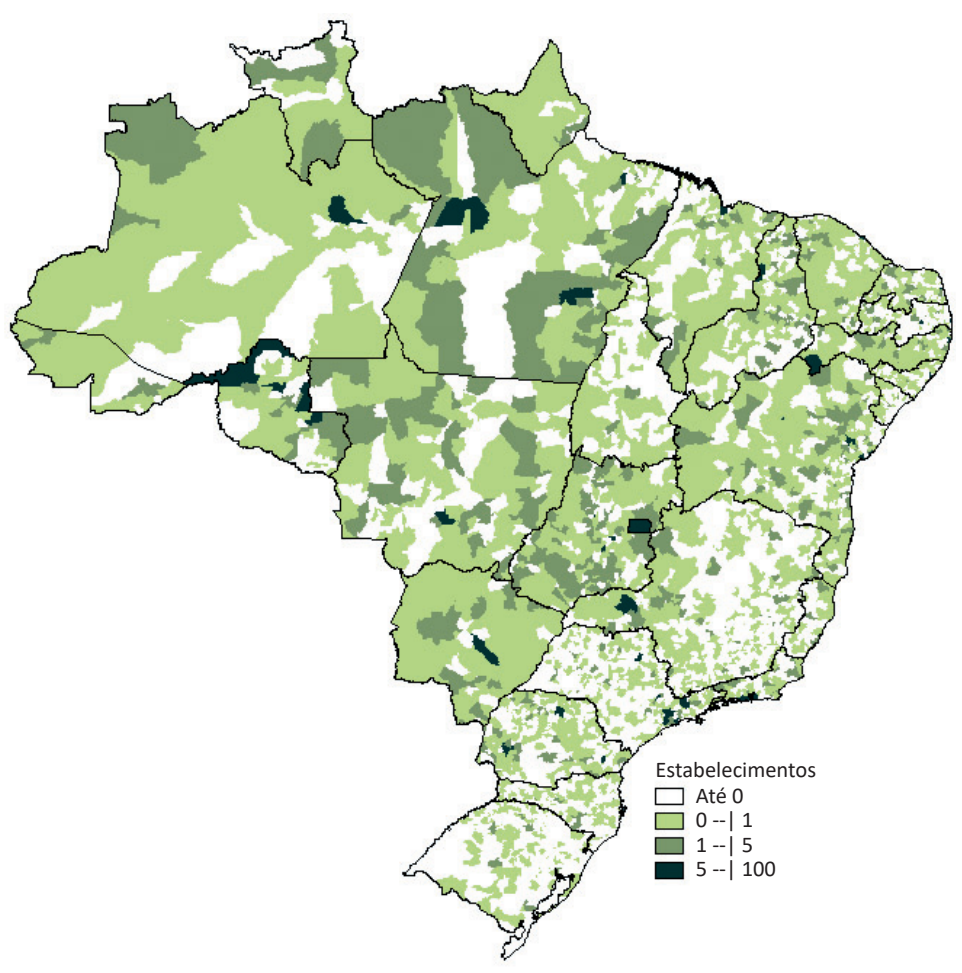

D. 100-299 leitos

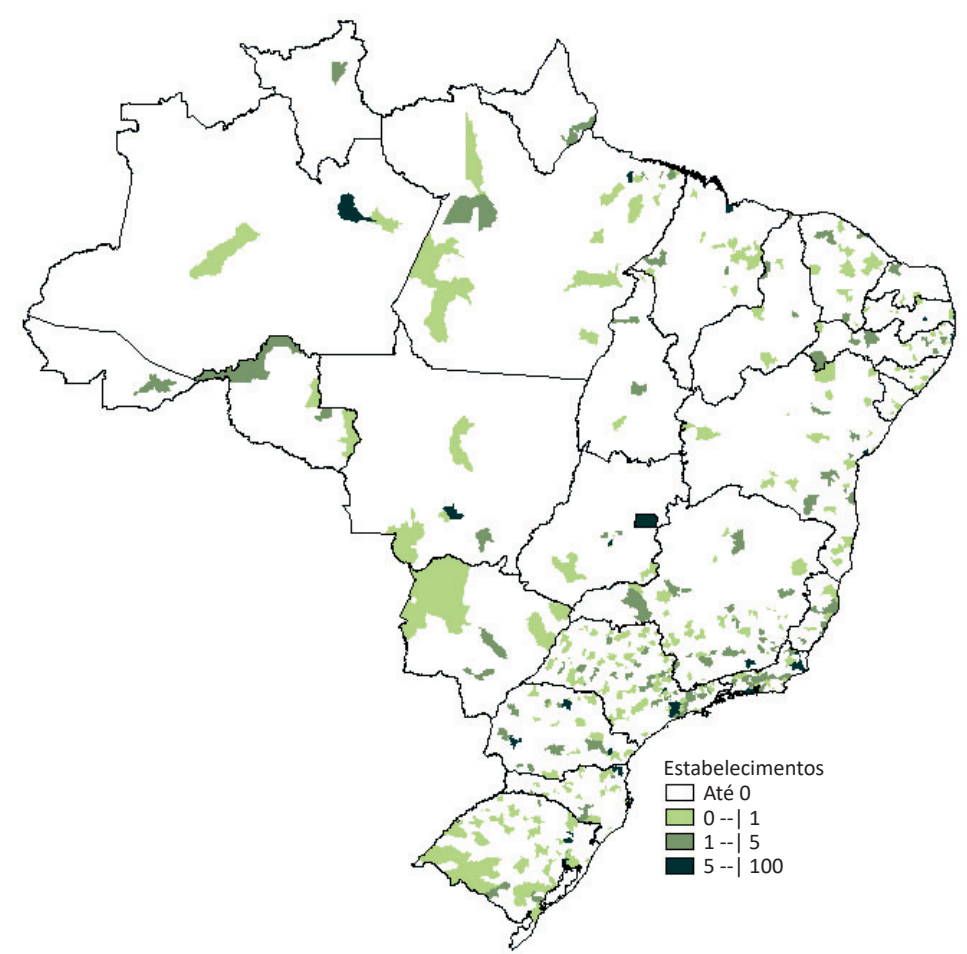

C. 50-99 leitos

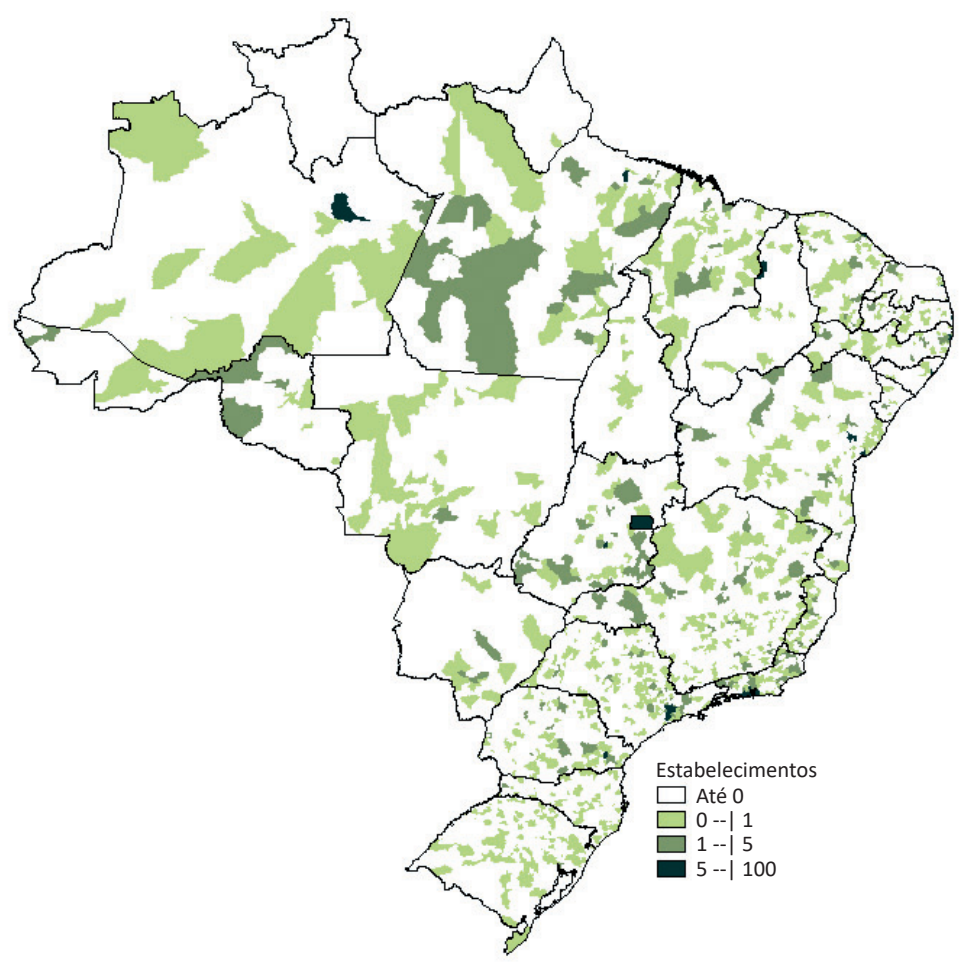

E. 300 leitos ou mais

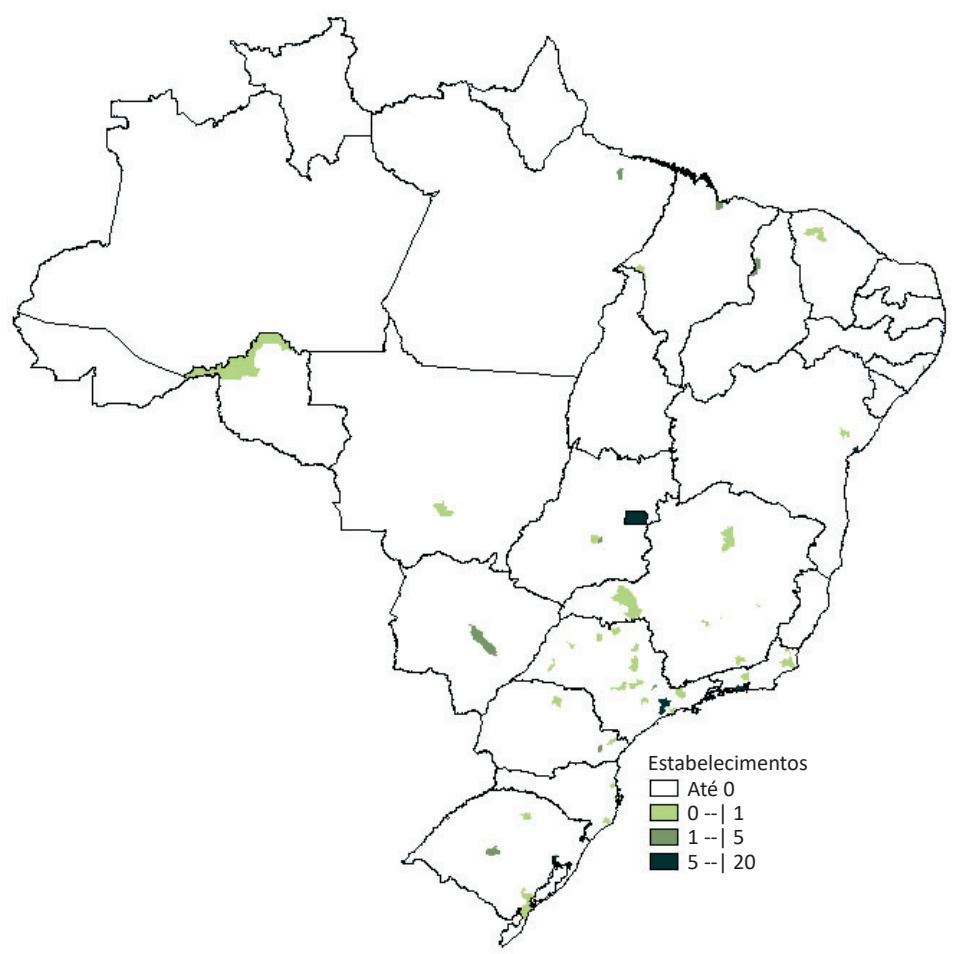

Fonte: elaborado pelas autoras, com base em dados do CNES referentes ao ano de 2013 (Brasil, 2014). 


\section{Leitos para internação}

No Brasil, em 2013, estavam disponíveis em torno de 430 mil leitos, sendo 296.131 leitos SUS (68\%) e 135.909 Não SUS (32\%). Mas essa distribuição é desigual, pois quando analisados os cinquenta municípios com o maior número de leitos no total, segundo classificação SUS ou Não SUS, observou-se que a oferta de leitos Não SUS é superior à oferta de leitos SUS em algumas cidades que dispunham de mais de 1.000 leitos (como Rio de Janeiro, Niterói e Santos), enquanto em outras cidades havia maior disponibilidade de leitos SUS do que Não SUS (por exemplo: São Paulo, Belo Horizonte, Fortaleza e Salvador).

A Figura 2 permite observar a distribuição dos municípios que ofertavam leitos de internação por SUS, Não SUS e ambos, simultaneamente. Apesar de ser possível verificar algumas áreas brancas, significando ausência de oferta de leitos de internação, percebe-se que a maior parte dos municípios dispunha de leitos SUS e Não SUS. Na região central e no sertão do país, observam-se alguns municípios onde só existia a oferta de leitos Não SUS, próximos a áreas sem qualquer oferta de leitos para internação.

Figura 2 - Leitos gerais Não SUS, SUS e ambos por município. Brasil - 2013

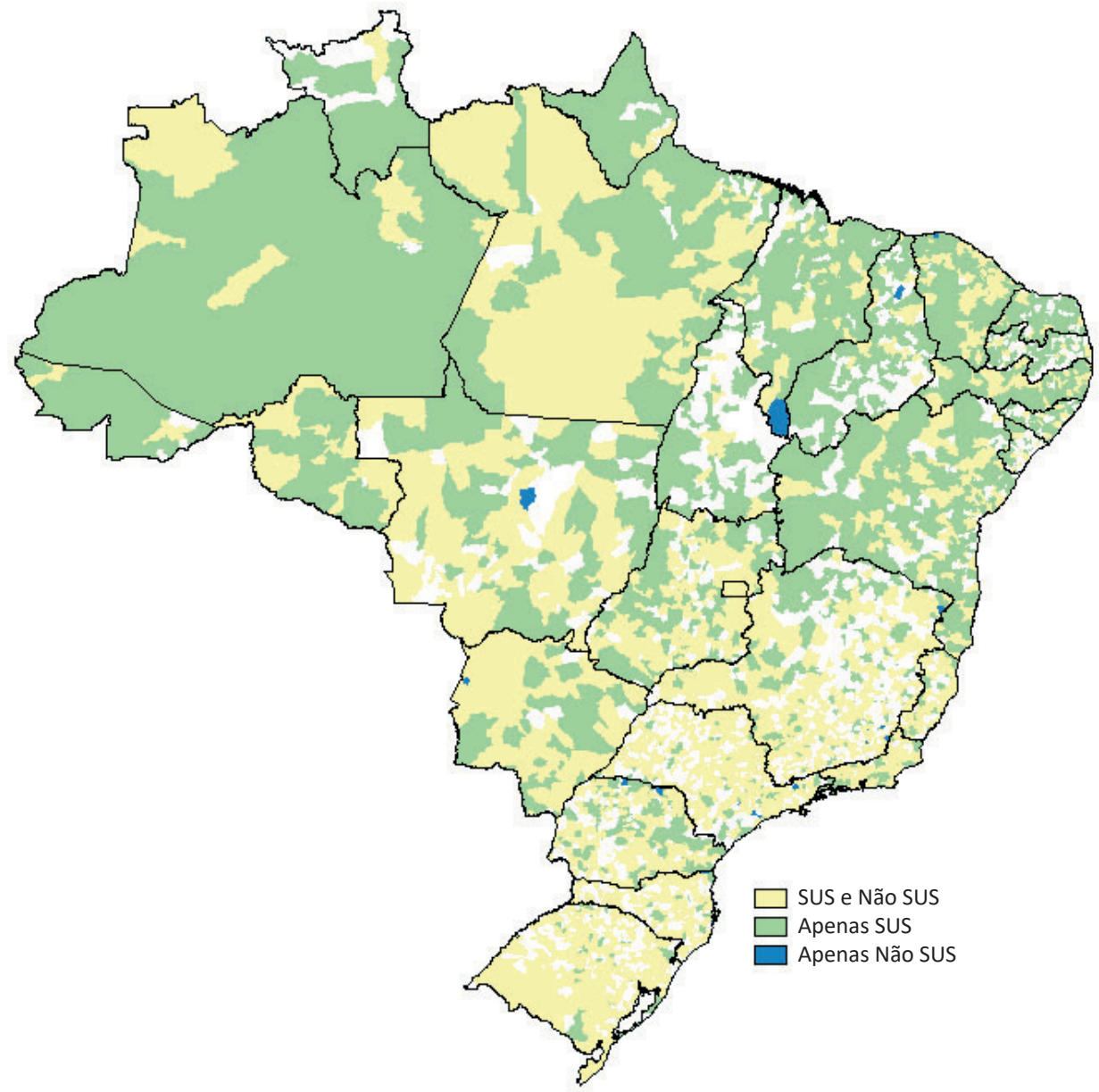

Fonte: elaborado pelas autoras, com base em dados do CNES referentes ao ano de 2013 (Brasil, 2014). 
Destaca-se que 19 municípios só dispunham de leitos Não SUS. ${ }^{3}$ Em 1.759 municípios apenas o SUS oferecia internação. Em 1.701 municípios eram oferecidos leitos SUS e Não SUS. A oferta de leitos SUS era maior em 1.537 municípios (216.070), representando mais do que o dobro da oferta Não SUS (97.229). Nos 163 municípios restantes com leitos para internação a oferta de leitos Não SUS (38.222 leitos) era 36\% maior que a oferta SUS (27.996 leitos). Mesmo sabendo que 80\% dos hospitais brasileiros têm menos de 100 leitos e que, destes, a maioria são leitos SUS, uma análise que permita fazer inferências sobre municípios ou hospitais onde investir requer um estudo mais aprofundado.

\section{Leitos de UTI}

No ano de 2013 havia 37.968 leitos de UTI distribuídos em 1.887 estabelecimentos e em 510 municípios (Tabela 3). Esses leitos de UTI estavam divididos entre SUS (18.970 - 50,3\%) e Não SUS (18.998 - 49,7\%).

Tabela 3 - Número e percentual de estabelecimentos e de municípios segundo número de leitos de UTI disponibilizados. Brasil -2013

\begin{tabular}{|l|c|c|c|c|}
\hline N. de Leitos & Estabelecimento & $\%$ & Município & $\%$ \\
\hline Até 5 leitos & 202 & 10,7 & 32 & 6,3 \\
\hline 6 a 10 leitos & 611 & 32,4 & 173 & 33,9 \\
\hline 11 ou mais & 1.074 & 56,9 & 305 & 59,8 \\
\hline Total & 1.887 & 100,0 & 510 & 100,0 \\
\hline
\end{tabular}

Fonte: elaborado pelas autoras, com base em dados do CNES referentes ao ano de 2013 (Brasil, 2014).

A oferta de leitos de UTI Não SUS, em alguns municípios centrais como São Paulo, Rio de Janeiro, Brasília e Niterói, era bastante superior à oferta de leitos SUS.

Na Figura 3 observam-se grandes vazios na oferta de leitos de UTI. Os leitos Não SUS estavam presentes em 374 municípios, sendo a única oferta de leito de UTI disponível em 49 municípios do país, com 642 leitos.

\footnotetext{
${ }^{3}$ São eles, com os respectivos códigos do IBGE: 210050 Alto Parnaíba, 221065 Sigefredo Pacheco, 230725 Jijoca de Jericoacoara, 311787 Confins, 314210 Miradouro, 314820 Patrocínio do Muriaé, 315130 Piraúba, 350380 Artur Nogueira, 352620 Juquitiba, 355480 Tremembé, 411095 Itaipulândia, 412390 Santa Mariana, 412450 Santo Inácio, 420580 Garuva, 421190 Palhoça, 430930 Guaíba, 500520 Ladário, 510100 Araguaiana, 510850 Vera.
} 
Figura 3 - Municípios por disponibilidade de leitos de UTI SUS, Não SUS e ambos. Brasil -2013

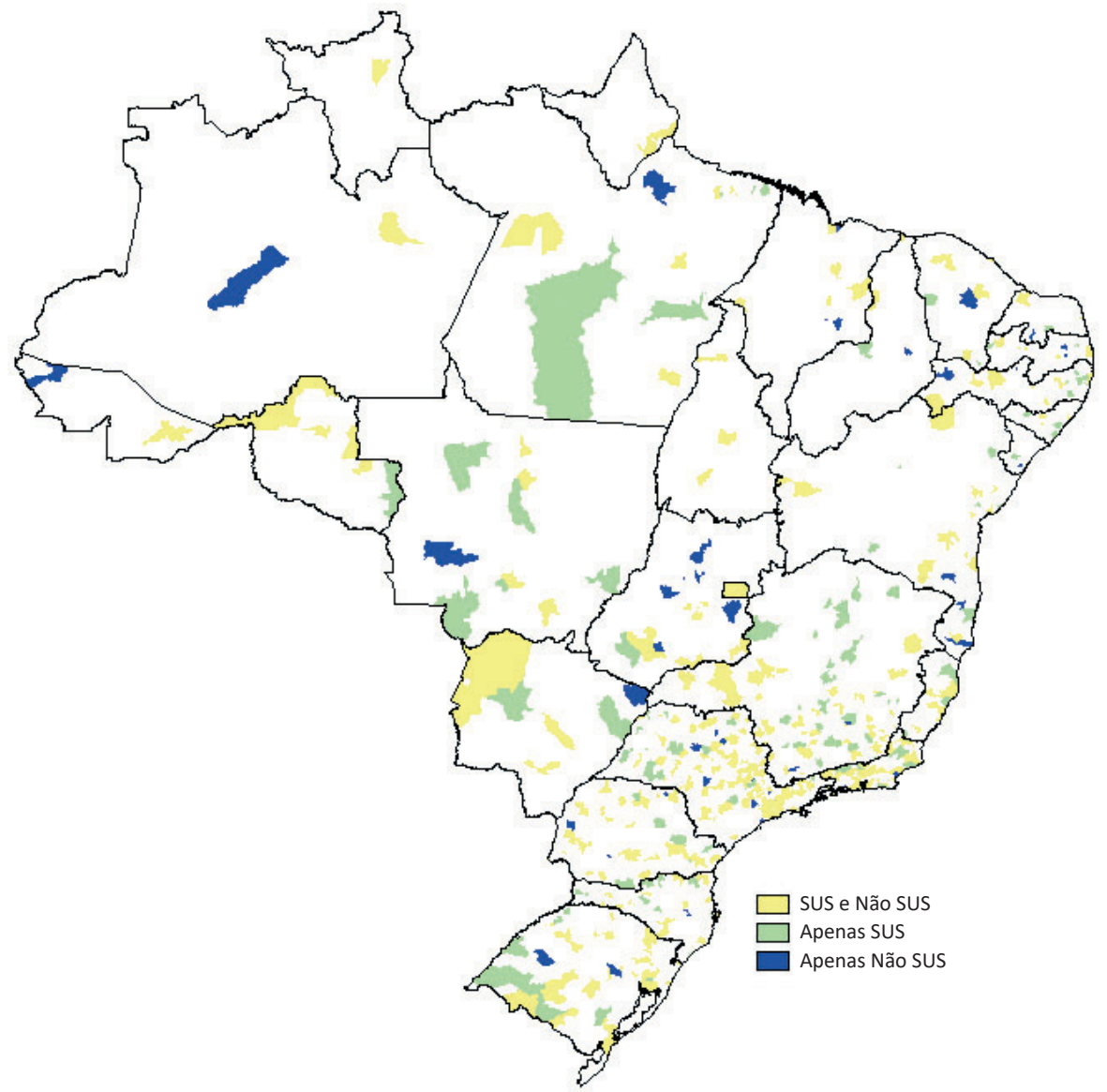

Fonte: elaborado pelas autoras, com base em dados do CNES referentes ao ano de 2013 (Brasil, 2014).

\section{Disponibilidade de estruturas para condições selecionadas}

\section{Leitos ortopédicos e neurocirúrgicos}

Por relacionarem-se ao serviço de alta complexidade do trauma, foram organizados e apresentados nesta seção os leitos de ortopedia e de neurocirurgia. Embora não sejam exclusivos para o tratamento do trauma, são indispensáveis para a atenção a essa condição.

No ano de 2013, aproximadamente 16.700 leitos ortopédicos eram oferecidos no país, sendo em torno de $80 \%$ ofertados pelo SUS. Os leitos ortopédicos estavam distribuídos em aproximadamente 640 municípios. Aproximadamente $25 \%$ dos municípios dispunham de apenas dois leitos, $50 \%$ disponibilizavam entre três e sete, $25 \%$ apresentavam entre oito e 17 leitos e $25 \%$ dispunham de 18 ou mais leitos. Os municípios de Rio de Janeiro e São Paulo dispunham de aproximadamente 1.200 leitos ortopédicos, cada um.

Os quase 5.000 leitos de neurocirurgia estavam distribuídos em 224 municípios. Aproximadamente $70 \%$ dos leitos eram ofertados pelo SUS. Em torno de $25 \%$ dos municípios tinham apenas 
três leitos, aproximadamente 25\% tinham entre quatro e seis, 25\% dispunham entre sete e 16 leitos e $25 \%$ tinham mais de 16 leitos, conforme Figuras 4 e 5.

Figura 4 - Leitos cirúrgicos de ortopedia segundo SUS, Não SUS e ambos. Municípios brasileiros - 2013

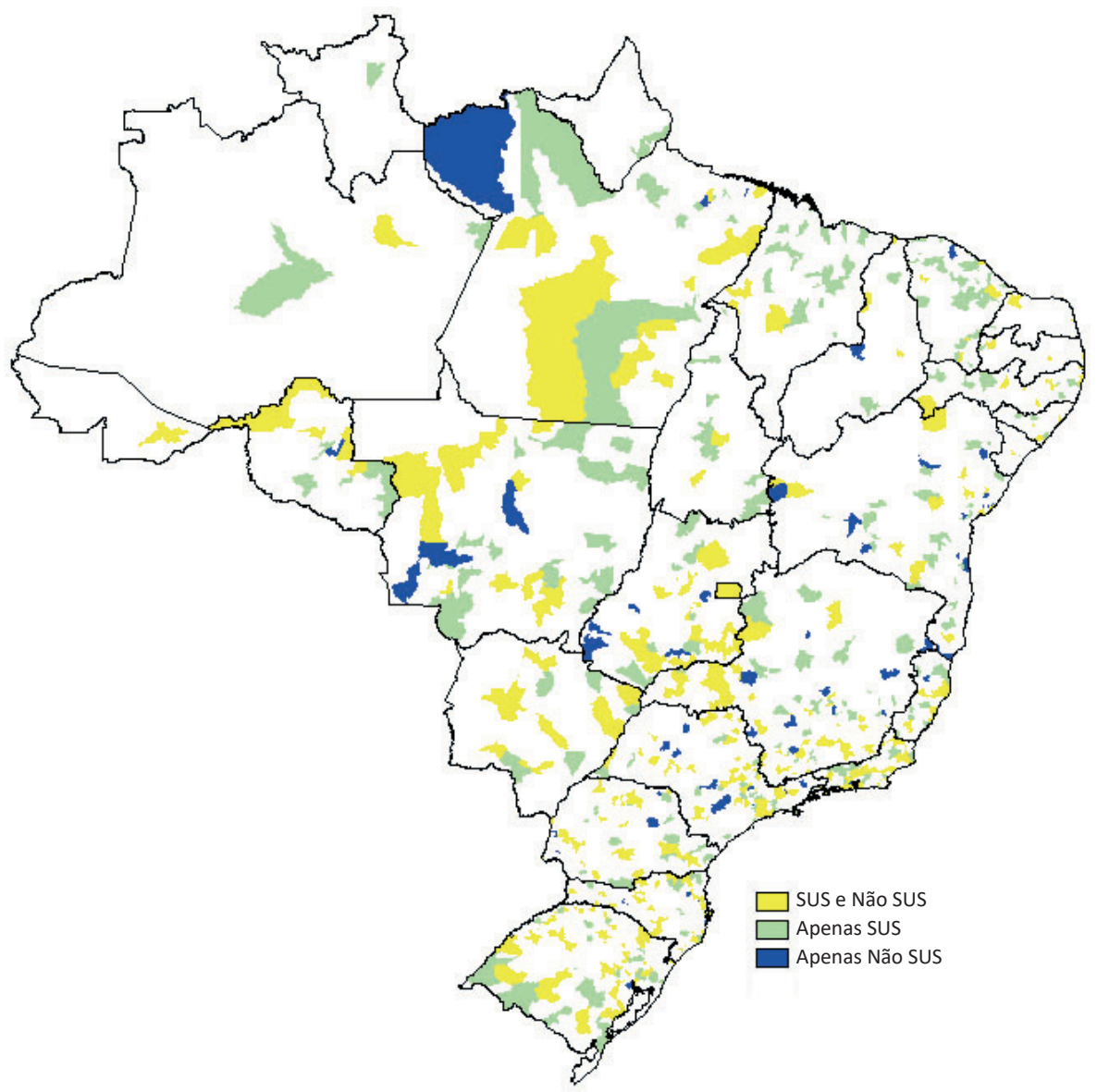

Fonte: elaborado pelas autoras, com base em dados do CNES referentes ao ano de 2013 (Brasil, 2014). 
Figura 5 - Leitos neurocirúrgicos segundo SUS, Não SUS e ambos. Municípios brasileiros - 2013

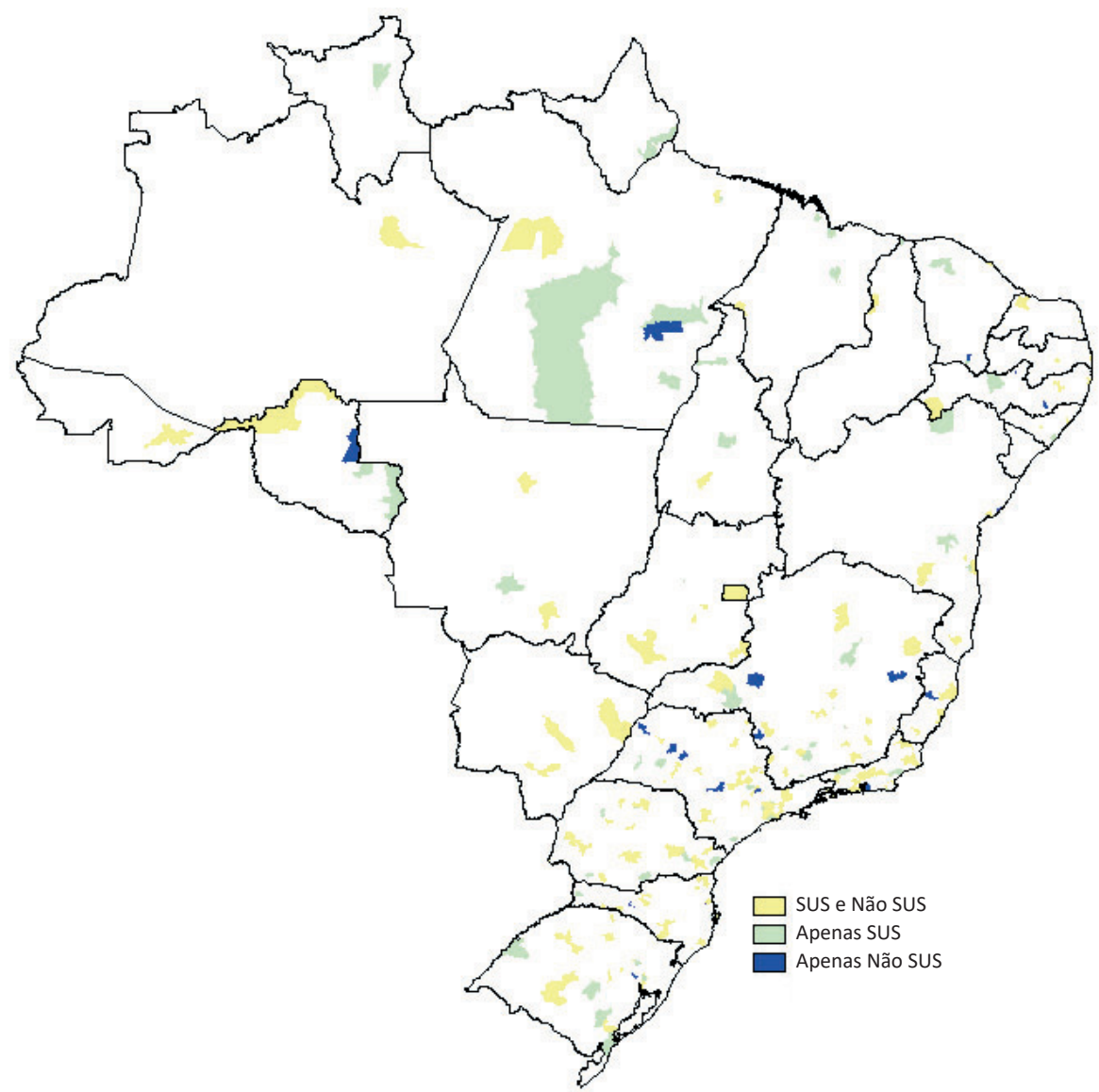

Fonte: elaborado pelas autoras, com base em dados do CNES referentes ao ano de 2013 (Brasil, 2014).

\section{Trauma}

Para que uma unidade de saúde esteja habilitada ao atendimento do trauma, segundo a política nacional do trauma, exige-se: disponibilidade de UTI, porte de mais de cem leitos, tomografia computadorizada, ressonância magnética, assistência de alta complexidade em neurocirurgia (este serviço inclui neurocirurgia e traumatologia, bem como os leitos de internação relacionados), hemoterapia, radiologia intervencionista, ou reabilitação. Essas oito estruturas foram analisadas em conjunto, pois se relacionam ao atendimento de trauma de alta complexidade. Quanto ao trauma de média complexidade, analisaram-se cinco de oito estruturas: disponibilidade de UTI, porte de mais de cem leitos, tomografia computadorizada, serviço de alta complexidade em neurocirurgia e hemoterapia.

\section{Estruturas específicas para a atenção ao trauma de alta complexidade}

Em relação às estruturas específicas para atenção ao trauma de alta complexidade, apenas 41 hospitais em 30 municípios detinham os oito itens necessários para habilitação ao atendimento ao trauma de alta complexidade, um número muito baixo diante da necessidade da população em de- 
corrência da transição demográfica. Já 99 hospitais em 64 municípios contavam com sete das oito estruturas analisadas.

Se fossem alocados recursos em cinquenta dos 99 hospitais com déficit de apenas uma das estruturas analisadas (um por município, em que o hospital com maior estrutura disponível dispõe de sete das oito analisadas), o Brasil mais que dobraria o número de municípios com capacidade de assistência ao trauma de alta complexidade, passando de trinta para oitenta municípios cobertos (Gráfico 6).

Gráfico 6 - Hospitais e municípios segundo número de estruturas existentes para trauma de alta complexidade. Brasil - 2013

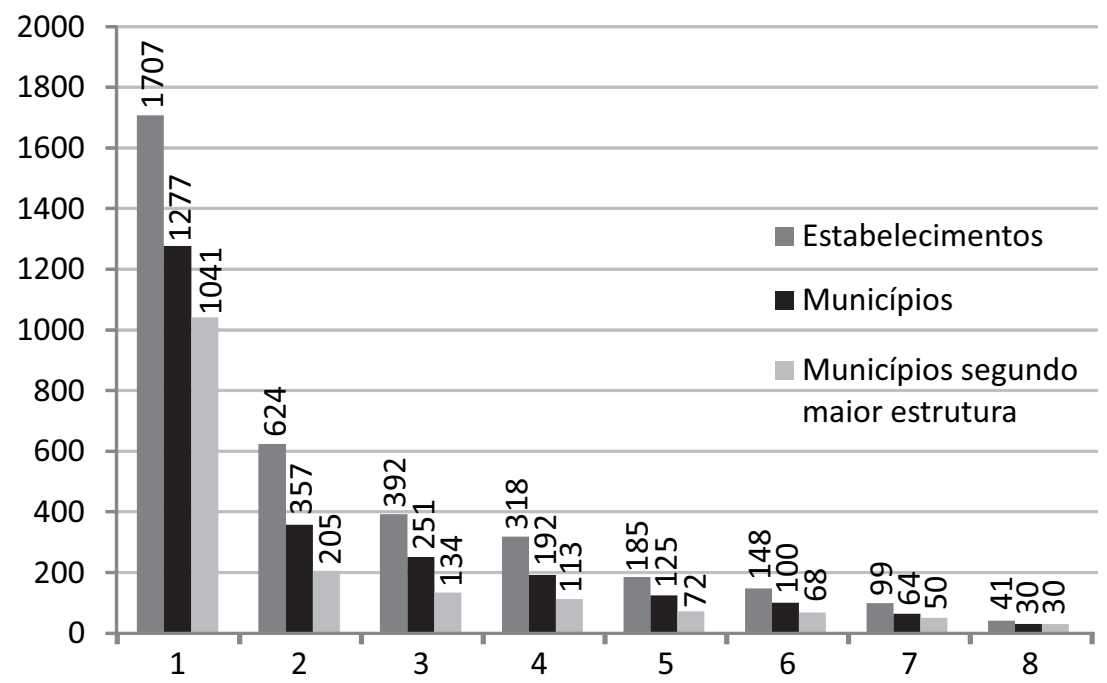

Fonte: elaborado pelas autoras, com base em dados do CNES referentes ao ano de 2013 (Brasil, 2014).

A categorização dos municípios com sete ou oito das oito estruturas para atendimento do trauma complexo indica a escassez de hospitais disponíveis para esse atendimento nas regiões Norte e Nordeste, além da concentração desses hospitais nas regiões Sudeste e Sul, especialmente nos municípios de São Paulo, Rio de Janeiro, Porto Alegre, Salvador, Belo Horizonte, Santos e Recife, com ao menos um hospital contendo as oito estruturas analisadas, além do maior número de hospitais com sete ou oito das estruturas selecionadas para análise. Em 14 municípios, havia pelo menos uma unidade de saúde com sete estruturas e também uma unidade de saúde com oito estruturas. Nesses municípios estavam 37 hospitais com sete das oito estruturas analisadas (Figura 6). 
Figura 6 - Municípios segundo estabelecimentos com sete ou oito estruturas das oito estruturas para trauma complexo. Brasil - 2013

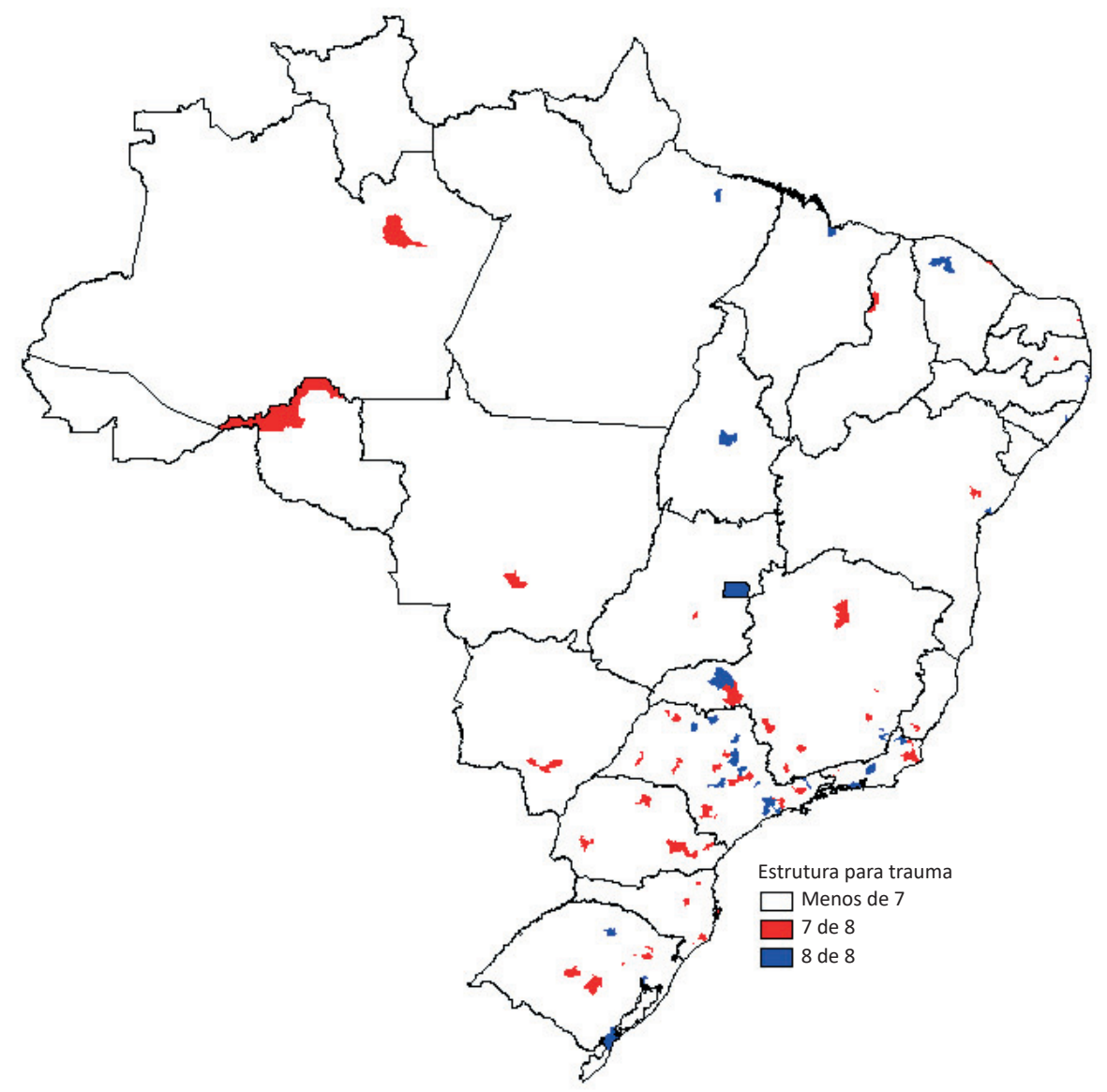

Fonte: elaborado pelas autoras, com base em dados do CNES referentes ao ano de 2013 (Brasil, 2014).

Entre os 41 estabelecimentos com as oito estruturas, 17 eram públicos, 21 eram privados sem fins lucrativos e três privados com fins lucrativos. Já entre os 99 estabelecimentos com sete das oito estruturas, 34 eram públicos, 56 privados sem fins lucrativos e nove privados com fins lucrativos.

Observando-se apenas hospitais com sete das oito estruturas analisadas, no Gráfico 7, identificam-se as seguintes deficiências, em ordem de volume: radiologia intervencionista (39 hospitais), ressonância magnética (trinta hospitais), reabilitação (16 hospitais), hemoterapia (nove hospitais), neurocirurgia e ortopedia-traumatologia (quatro hospitais), mais de cem leitos (um hospital). 
Gráfico 7 - Hospitais com sete estruturas para trauma complexo segundo estrutura deficiente. Brasil $-2013$

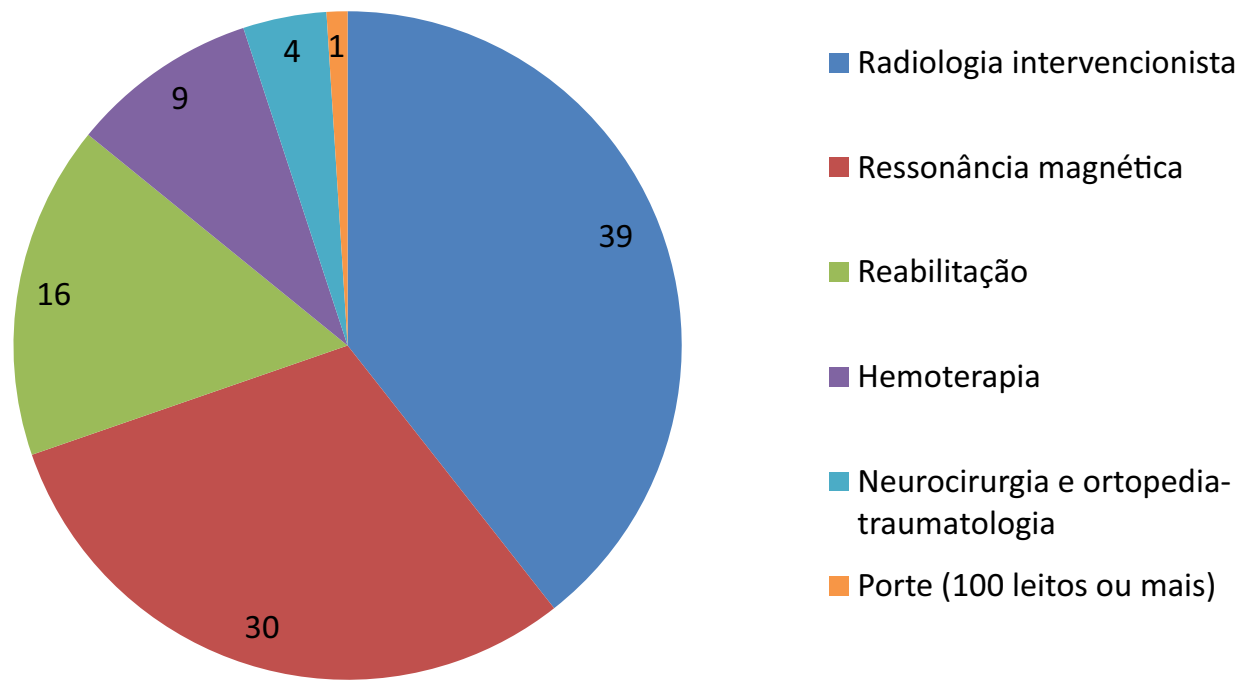

Fonte: elaborado pelas autoras, com base em dados do CNES referentes ao ano de 2013 (Brasil, 2014).

\section{Estruturas específicas para a atenção ao trauma de média complexidade}

Para análise das estruturas do trauma de média complexidade, consideraram-se cinco estruturas: disponibilidade de UTI, porte de mais de cem leitos, tomografia computadorizada, serviço de alta complexidade em neurocirurgia e hemoterapia.

Existiam 245 estabelecimentos que contemplavam as cinco estruturas, distribuídos em 140 municípios (Gráfico 8). Com quatro dessas cinco estruturas, eram 343 estabelecimentos em 196 municípios. Havia um número extremamente reduzido de hospitais com esse atendimento nas regiões Norte e Nordeste, e uma situação um pouco melhor na região Sudeste, especialmente no estado de São Paulo.

São Paulo, Rio de Janeiro, Belo Horizonte, Brasília, Salvador, Recife, Porto Alegre e Manaus se destacam com o maior número de hospitais com quatro ou cinco das estruturas analisadas (Figura 7). 
Gráfico 8 - Hospitais e municípios segundo número de estruturas existentes para trauma de média complexidade. Brasil - 2013

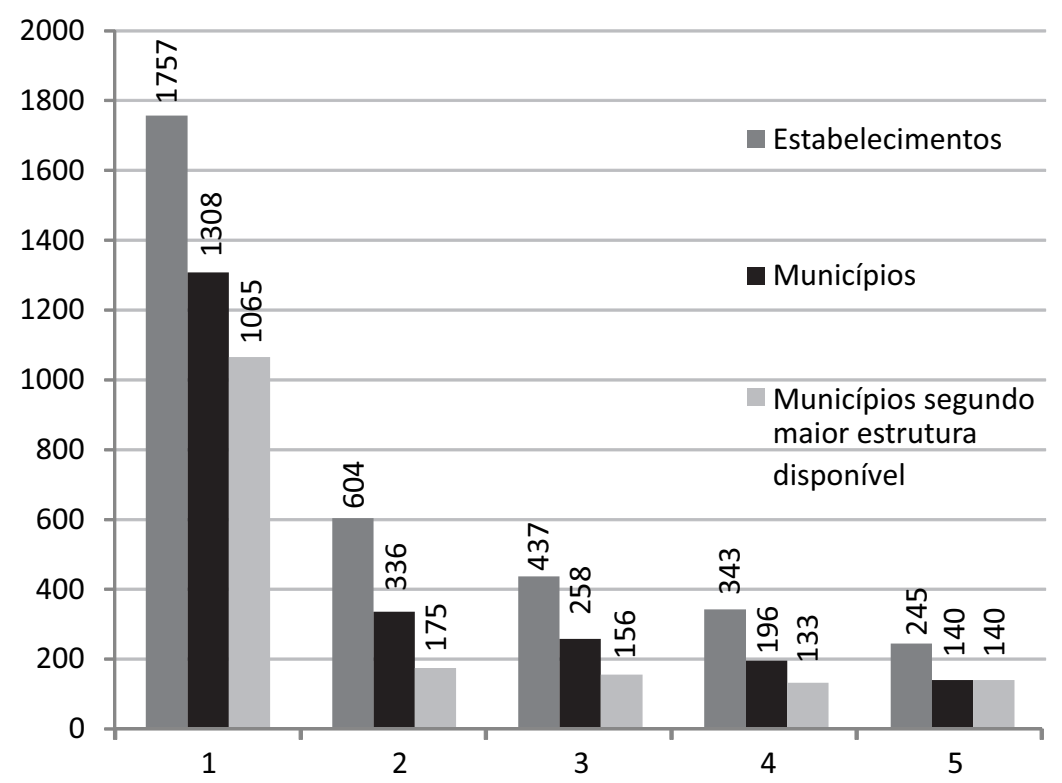

Fonte: elaborado pelas autoras, com base em dados do CNES referentes ao ano de 2013 (Brasil, 2014).

Figura 7 - Municípios segundo estabelecimentos com quatro ou cinco estruturas das 5 estruturas para trauma de média complexidade. Brasil - 2013

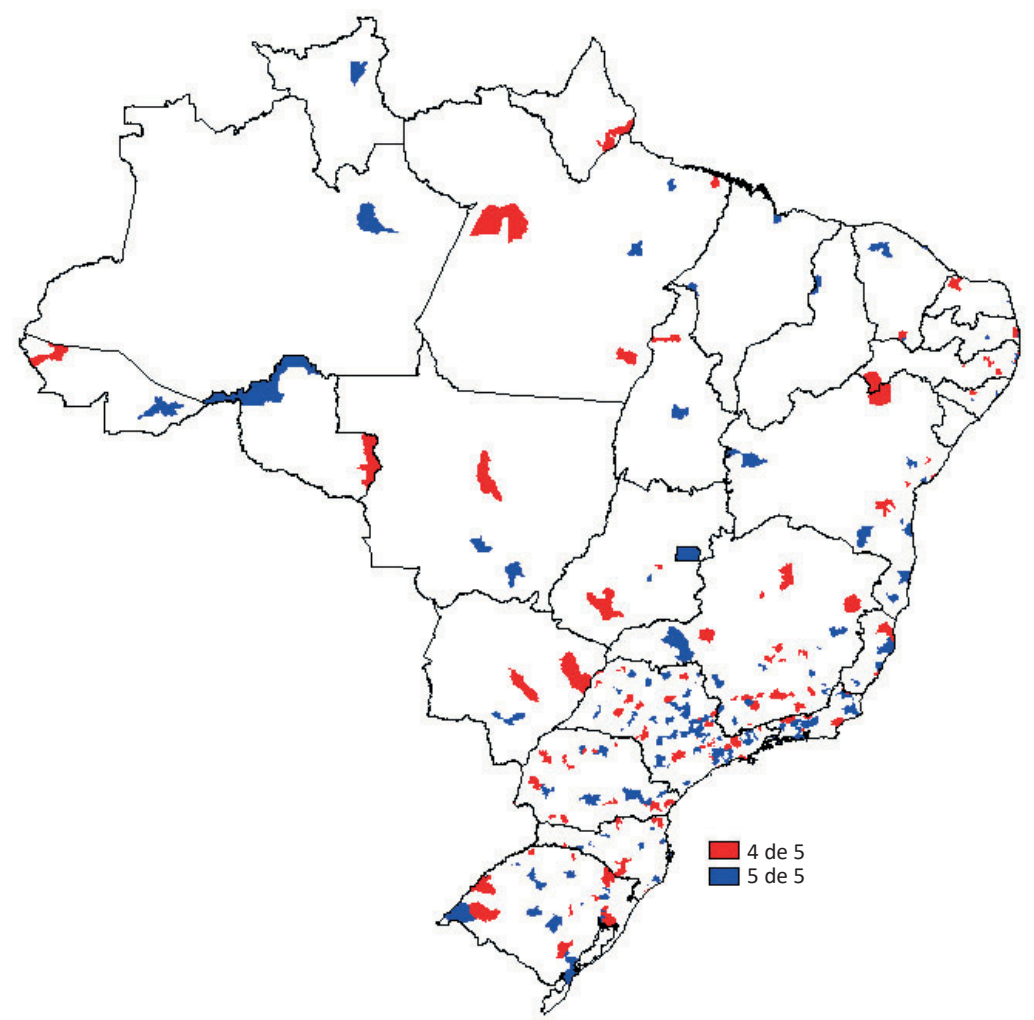

Fonte: elaborado pelas autoras, com base em dados do CNES referentes ao ano de 2013 (Brasil, 2014). 
Entre os 245 estabelecimentos com as cinco estruturas, 102 eram públicos, 122 privados sem fins lucrativos e 21 privados com fins lucrativos. Já entre os 343 estabelecimentos com quatro das cinco estruturas, 136 eram públicos, 156 privados sem fins lucrativos e 51 privados com fins lucrativos.

Observando-se apenas hospitais com quatro das cinco estruturas analisadas (Gráfico 9), identificaram-se as seguintes deficiências, em ordem de volume: neurocirurgia e ortopedia-traumatologia (237 hospitais), hemoterapia (51 hospitais), tomografia computadorizada (26 hospitais), mais de cem leitos (24 hospitais) e presença de UTI (cinco hospitais).

Gráfico 9 - Número de hospitais com quatro das cinco estruturas para trauma de média complexidade, segundo deficiência. Brasil - 2013

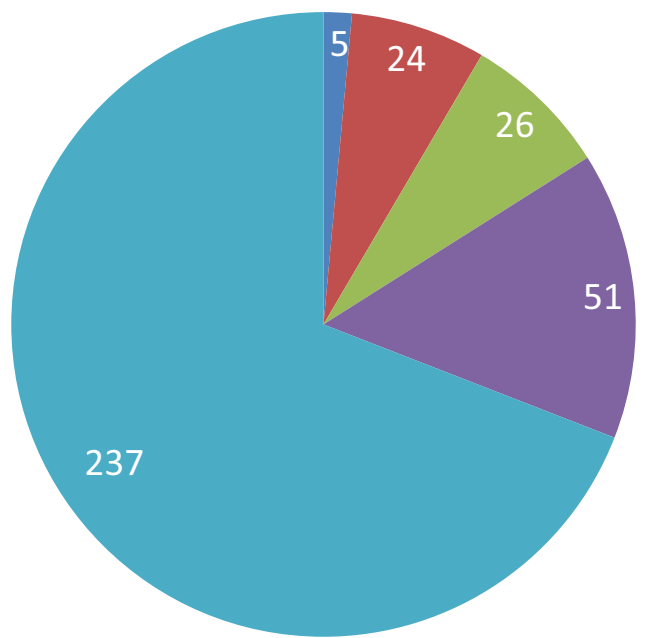

Porte (100 leitos ou mais)

Tomografia computadorizada

Hemoterapia

Neurocirurgia e ortopedia-

traumatologia

Fonte: elaborado pelas autoras, com base em dados do CNES referentes ao ano de 2013 (Brasil, 2014).

\section{Doença renal}

\section{Estruturas específicas para a atenção ao doente renal}

Em relação às estruturas específicas para a atenção ao doente renal, dos 21,2 mil equipamentos para hemodiálise cadastrados no CNES, cerca de vinte mil estão informados como equipamentos em uso, distribuídos em 404 municípios. Destacam-se com o maior número os municípios de São Paulo, Rio de Janeiro, Belo Horizonte, Recife, Fortaleza e Brasília. Em sua grande maioria, os municípios que dispunham desses equipamentos atendiam pacientes SUS e Não SUS.

Pouco mais de três mil equipamentos estavam em estabelecimentos não habilitados como unidades ou centros de referência de alta complexidade em nefrologia, e 47 municípios apenas tinham equipamentos em unidades não habilitadas (Figura 8). 
Figura 8 - Estabelecimentos com equipamento de hemodiálise segundo habilitação. Brasil - 2013

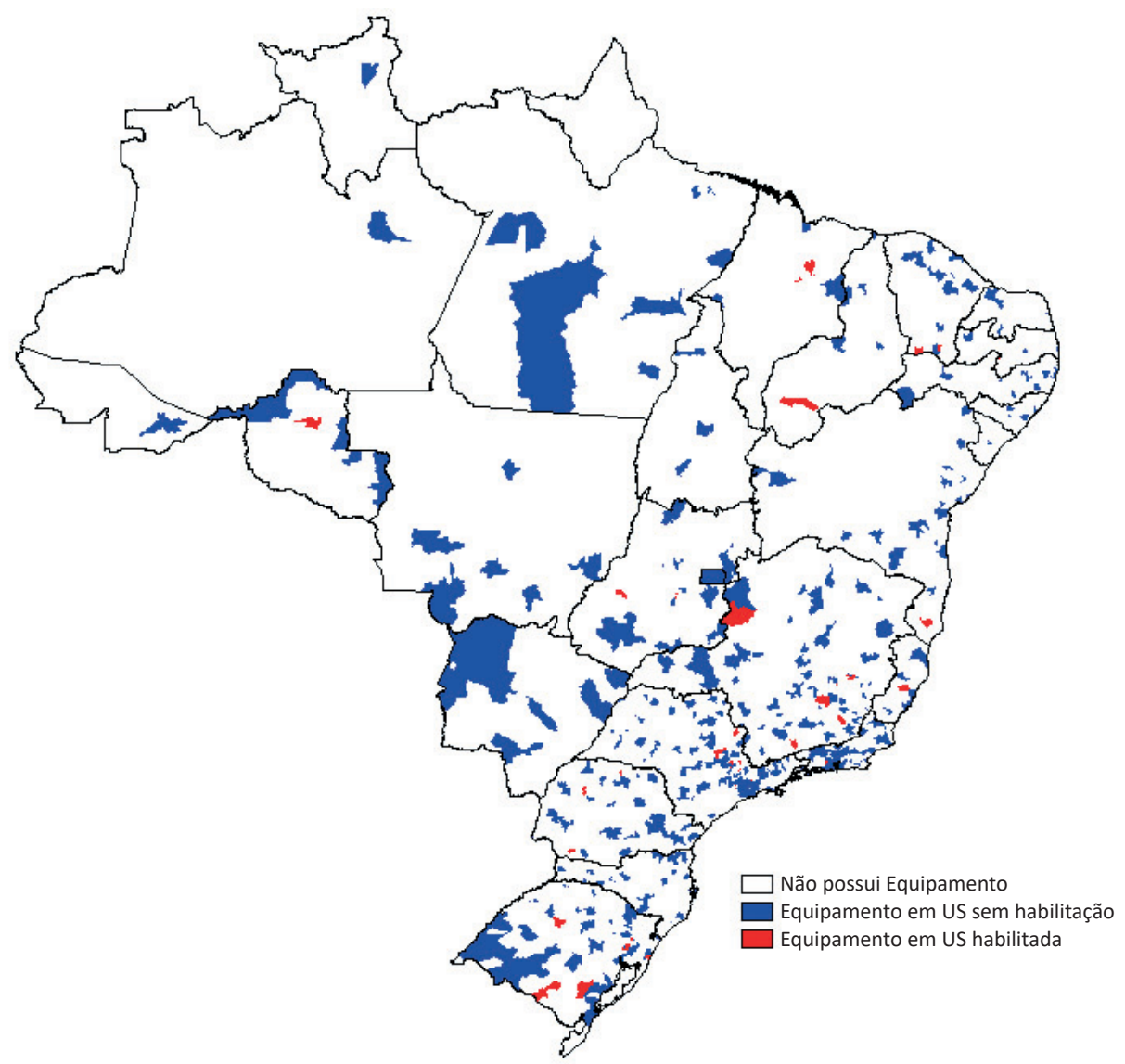

Fonte: elaborado pelas autoras, com base em dados do CNES referentes ao ano de 2013 (Brasil, 2014).

Em 2013 existiam cadastrados no CNES 143 estabelecimentos habilitados em transplante renal, distribuídos em 68 municípios de 23 estados. No Sul havia a maior disponibilidade desse serviço, e no Norte a menor. Os estados de Rondônia, Roraima, Amapá e Tocantins não contavam com serviço habilitado para transplante renal (Figura 9). 
Figura 9 - Municípios com serviço de transplante renal. Brasil - 2013

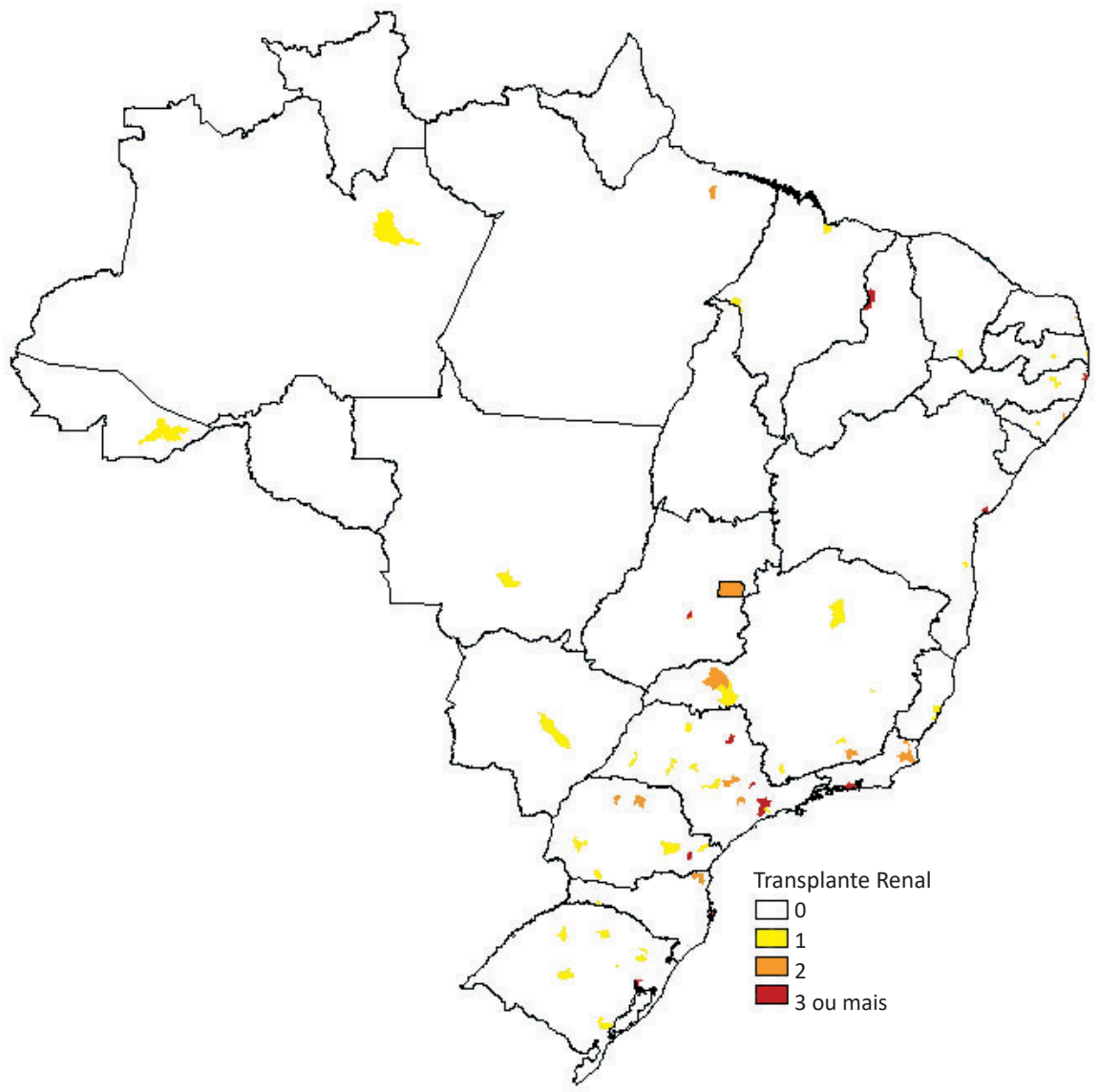

Fonte: elaborado pelas autoras, com base em dados do CNES referentes ao ano de 2013 (Brasil, 2014).

A maioria (mais de 70\%) dos equipamentos para hemodiálise do país está em estabelecimentos de natureza privada com fins lucrativos (Gráfico 10). Em Roraima e no Sergipe havia apenas equipamentos em estabelecimentos dessa natureza. Equipamentos em estabelecimentos públicos constituíam a minoria, não alcançando $8 \%$ do total.

Dos estabelecimentos habilitados para transplante renal, 50\% eram privados sem fins lucrativos e 27\% eram públicos. Amazonas, Alagoas, Paraíba, Sergipe, Alagoas, Espírito Santo, Paraná, Mato Grosso do Sul e Mato Grosso não dispunham de estabelecimentos públicos aptos para realizar transplante renal, mas sim estabelecimentos privados. 
Gráfico 10 - Equipamentos para hemodiálise e serviços habilitados para transplante renal segundo natureza jurídica do estabelecimento. Brasil - 2013

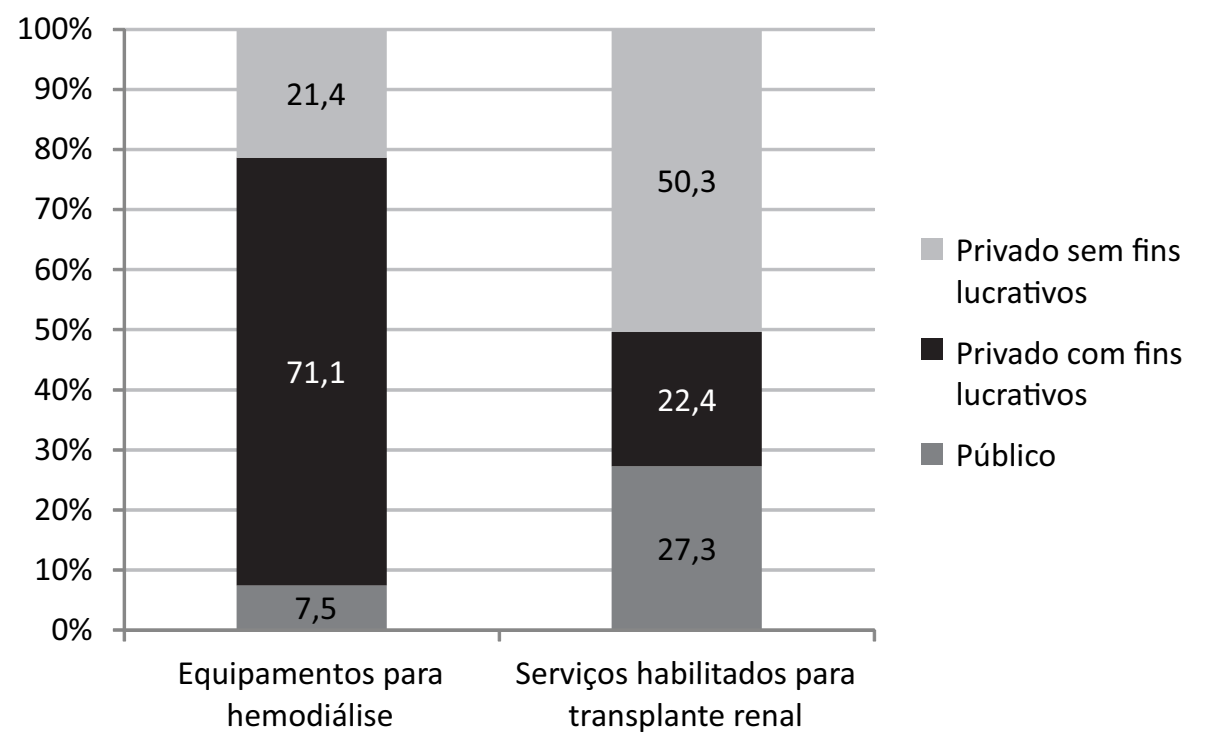

Fonte: elaborado pelas autoras, com base em dados do CNES referentes ao ano de 2013 (Brasil, 2014).

\section{Doenças cardíacas}

\section{Leitos clínicos de cardiologia}

Em relação aos leitos clínicos de cardiologia, em 2013 estavam disponíveis 7.730 leitos clínicos de cardiologia, sendo em torno de 60\% (4.522) oferecidos pelo SUS em todas as regiões do Brasil, embora com muitos vazios principalmente nas regiões Norte e Nordeste (Figura 10). Os leitos clínicos de cardiologia estavam distribuídos em 404 municípios. Em torno de 30\% desses municípios contavam com até dois leitos, aproximadamente $20 \%$ tinham entre três e cinco leitos, em torno de $25 \%$ entre seis e 13 leitos, e $25 \%$, 14 ou mais leitos.

Há em torno de oitenta municípios que oferecem, exclusivamente, leitos clínicos de cardiologia Não SUS. Entre eles, destacam-se São Gonçalo (RJ), Cruz das Almas e Olinda (PE), Osasco, São José do Rio Preto e São José dos Campos (SP).

Para analisar os municípios que oferecem leitos clínicos de cardiologia exclusivos SUS, a Figura 10 permite identificar a dispersão da presença desses leitos, que não se restringe às capitais ou regiões litorâneas. 
Figura 10 - Municípios com leitos clínicos de cardiologia. Brasil - 2013

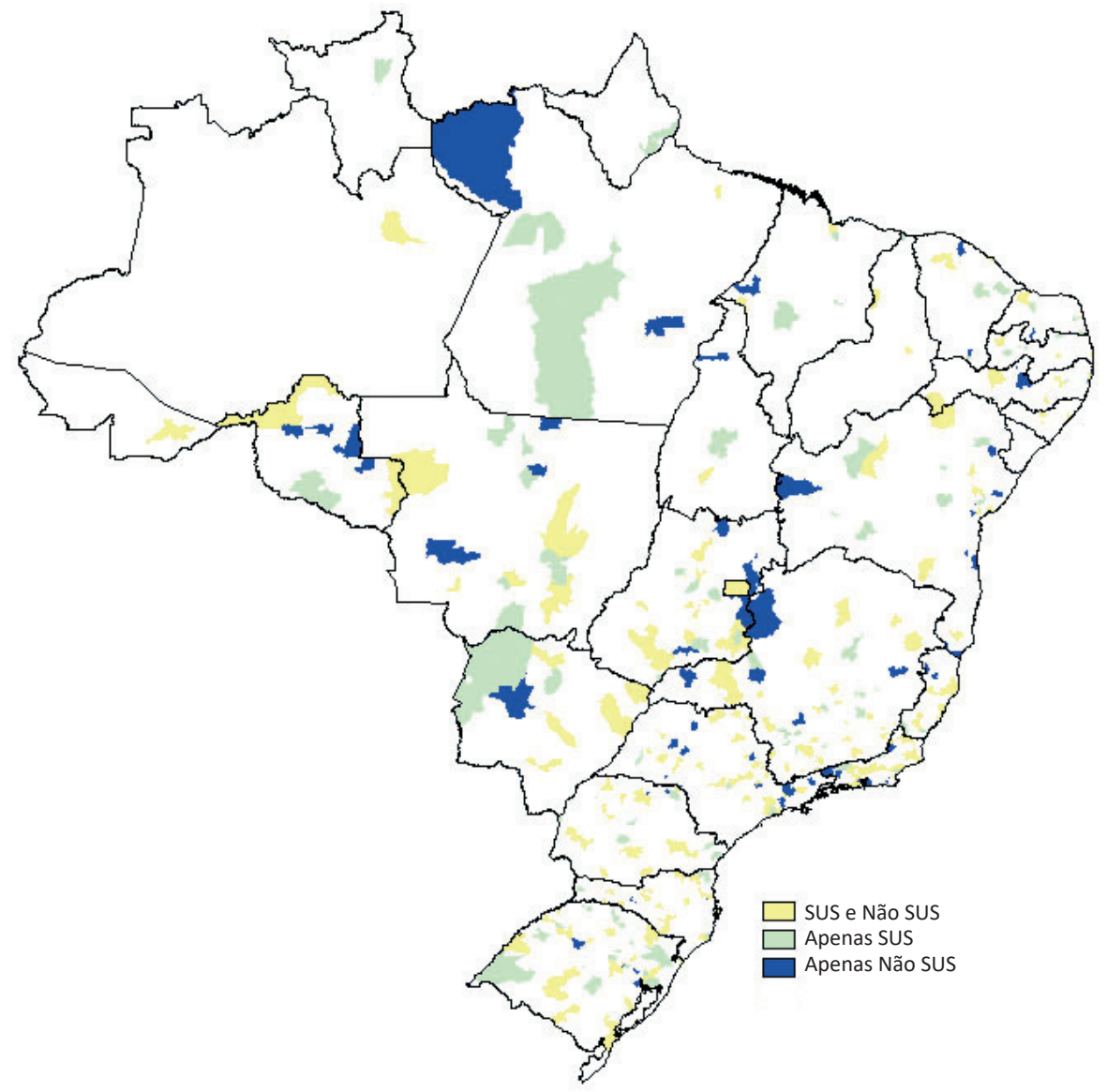

Fonte: elaborado pelas autoras, com base em dados do CNES referentes ao ano de 2013 (Brasil, 2014).

\section{Leitos cirúrgicos de cardiologia}

No caso dos leitos cirúrgicos de cardiologia, em 2013 eram ofertados 5.476 leitos cirúrgicos de cardiologia em 176 municípios. Desses leitos, 3.106 (57\%) eram SUS e 2.370 (43\%) Não SUS. Em 46 municípios a oferta é exclusiva Não SUS. Em Niterói e em Feira de Santana a oferta de leitos Não SUS chega a ser superior em dez vezes e cinco vezes à oferta de leitos SUS, respectivamente. Em Curitiba, Belém e Salvador a oferta da rede privada também era expressiva, próxima do dobro da quantidade de leitos SUS. À semelhança dos leitos clínicos de cardiologia, observam-se grandes áreas vazias em todo o país, principalmente nas regiões Norte, Nordeste e Centro-Oeste (Figura 11). 
Figura 11 - Leitos de cirurgia cardíaca. Municípios Brasileiros - 2013

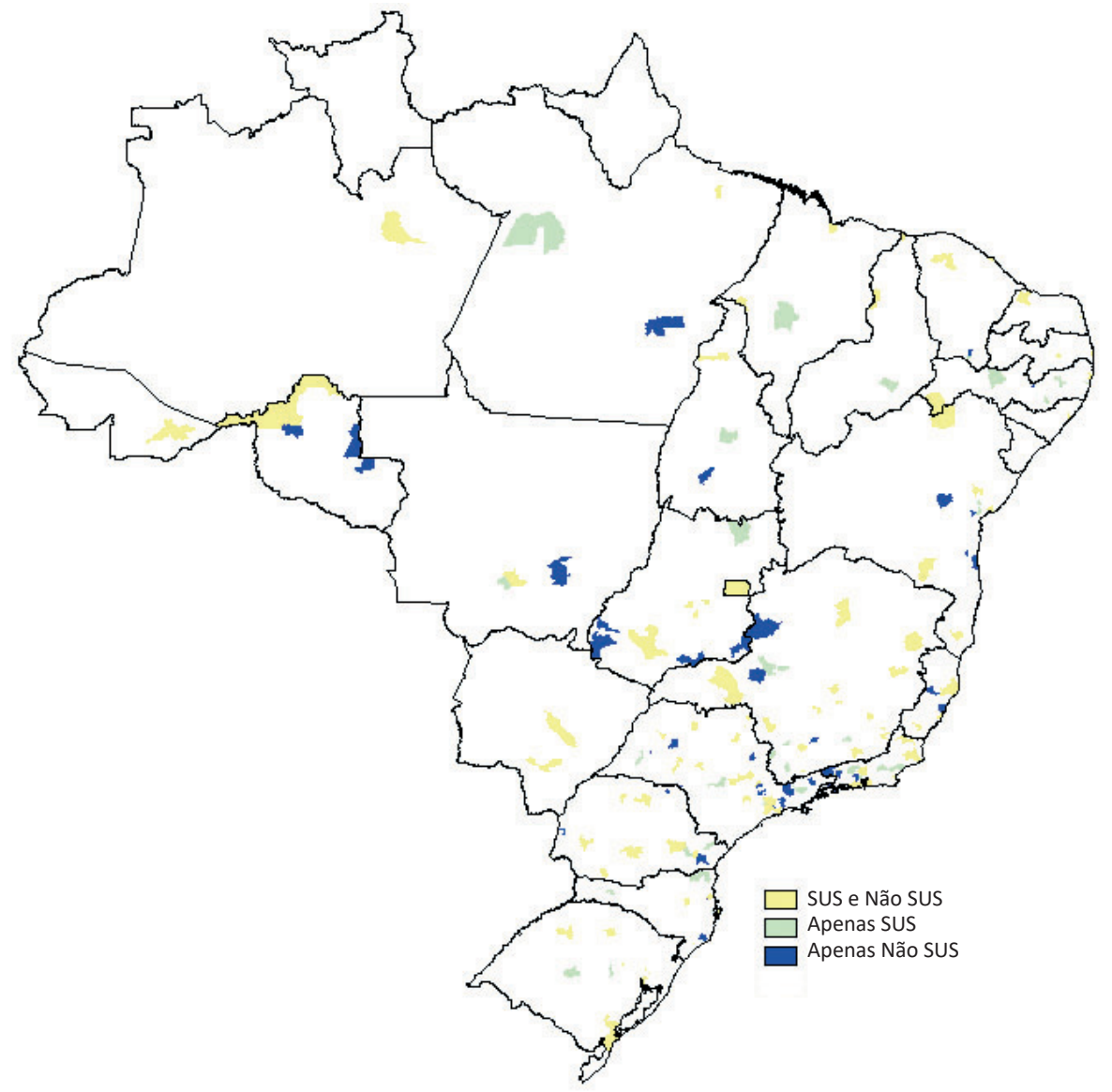

Fonte: elaborado pelas autoras, com base em dados do CNES referentes ao ano de 2013 (Brasil, 2014).

\section{Hemodinâmica}

Em relação à hemodinâmica, a Figura 12 mostra a distribuição dos equipamentos de hemodinâmica no Brasil por município. Em torno de 740 equipamentos estavam distribuídos em 190 municípios em 2013. Aproximadamente 50\% desses municípios tinham apenas um equipamento, 30\% tinham dois equipamentos e $20 \%$ tinham três ou mais equipamentos.

Em 17 municípios, menos de 100\% dos equipamentos existentes estavam registrados como em funcionamento. Destaca-se que em um município menos da metade dos equipamentos estava em uso. Como já salientado na análise de outros equipamentos, o registro do dado "em uso" carece de validação, pois essa informação é importante para indicar possíveis pontos de estrangulamento da capacidade de oferta e orientar possíveis investimentos específicos para realocação de recursos físicos ou de aporte de recursos. 
Figura 12 - Distribuição dos equipamentos de hemodinâmica, por município. Brasil -2013

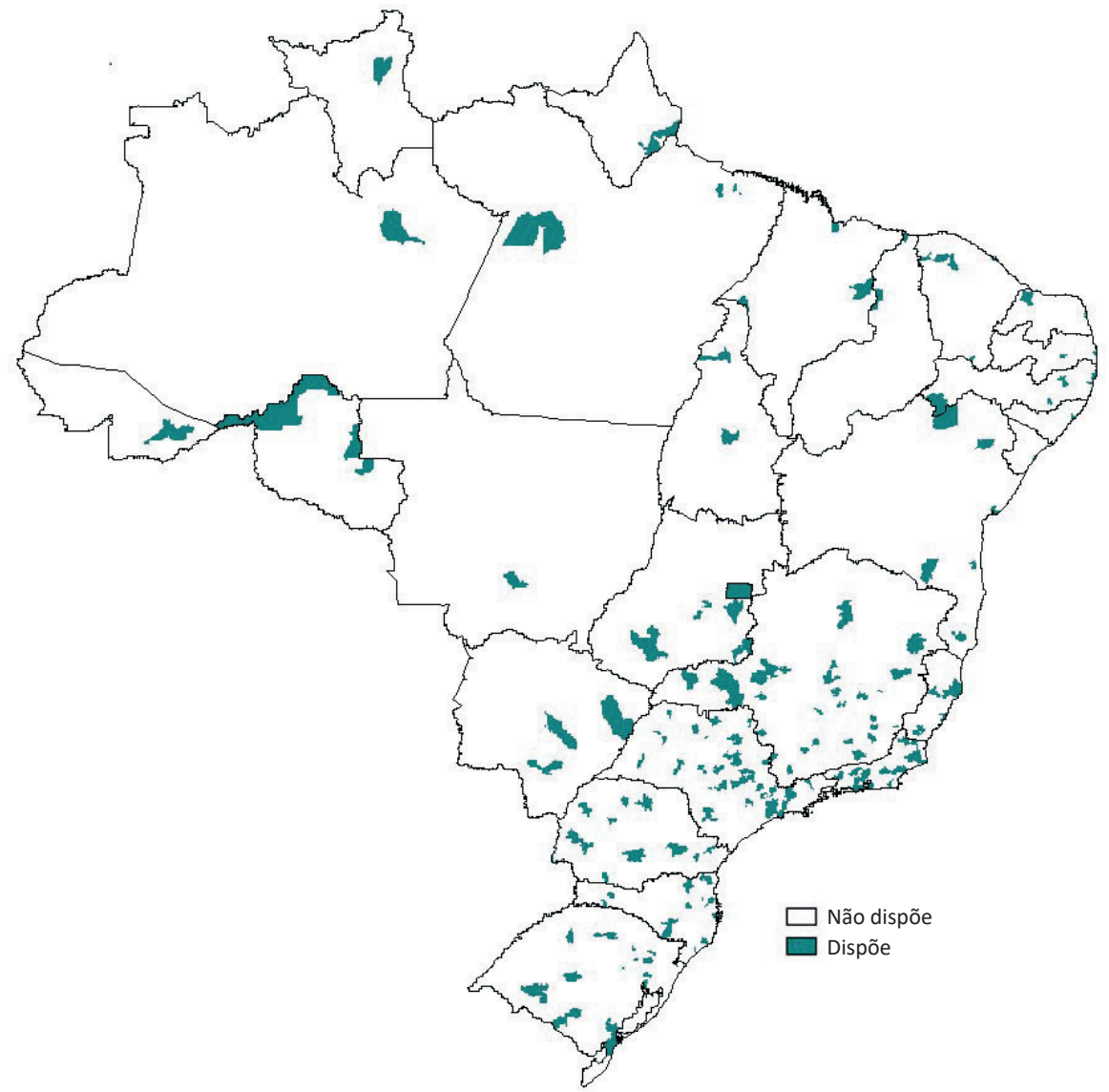

Fonte: elaborado pelas autoras, com base em dados do CNES referentes ao ano de 2013 (Brasil, 2014).

\section{Circulação extracorpórea}

No caso da circulação extracorpórea, em 2013 eram 1.287 aparelhos em uso, distribuídos em 235 municípios, conforme distribuição espacial apresentada na Figura 13. Entre os municípios com o equipamento, em torno de 50\% dispunham de apenas um, $25 \%$ apresentavam entre dois e três e $25 \%$, quatro ou mais. Destaca-se que Natal tinha 249 equipamentos (31 equipamentos/100 mil habitantes), ao passo que São Paulo tinha 116 e Rio de Janeiro 66 (1 equipamento/100 mil habitantes), indicando possível não atualização no CNES ou distorção de oferta. 
Figura 13 - Distribuição dos equipamentos de circulação extracorpórea, por município. Brasil - 2013

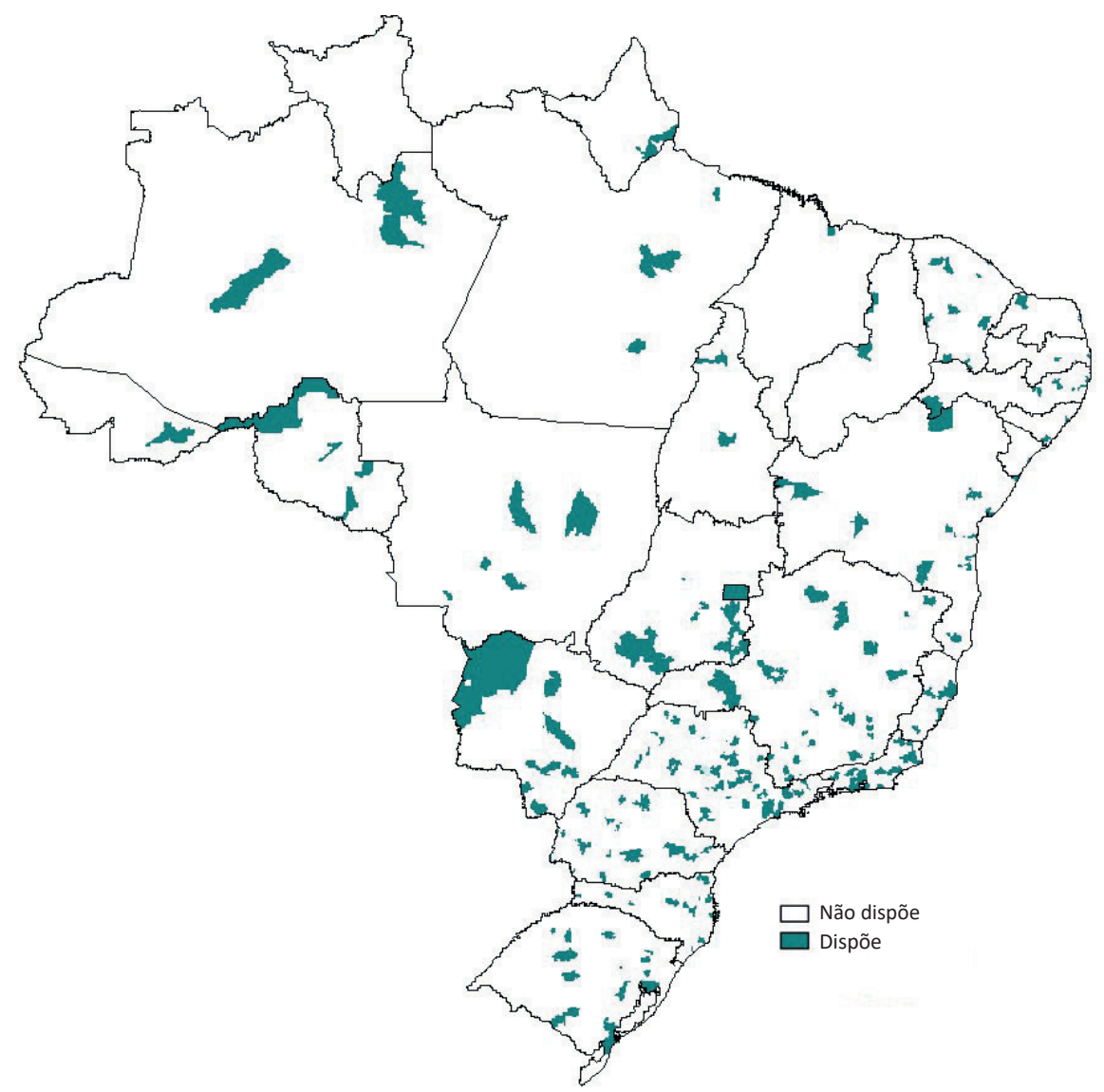

Fonte: elaborado pelas autoras, com base em dados do CNES referentes ao ano de 2013 (Brasil, 2014).

\section{Estruturas específicas para a cirurgia cardíaca}

Em relação à cirurgia cardíaca, em 2013 existiam 546 estabelecimentos habilitados para a realização de cirurgia cardíaca no Brasil, dos quais 187 estavam cadastrados como serviços que realizam procedimentos em pediatria e 359 em adulto. Esses estabelecimentos estavam distribuídos em 156 municípios de 25 estados, com destaque para Rio de Janeiro, São Paulo, Belo Horizonte, Fortaleza, Salvador e São Luís, onde havia o maior número de estabelecimentos com esses serviços (Figura 14).

Dos estabelecimentos com cirurgia cardíaca em pediatria, 33,7\% eram de natureza privada com fins lucrativos e entre os estabelecimentos com cirurgia cardíaca para adulto, 37,9\% eram privados com fins lucrativos (Gráfico 11). 
Figura 14 - Municípios com serviço de cirurgia cardíaca. Brasil - 2013

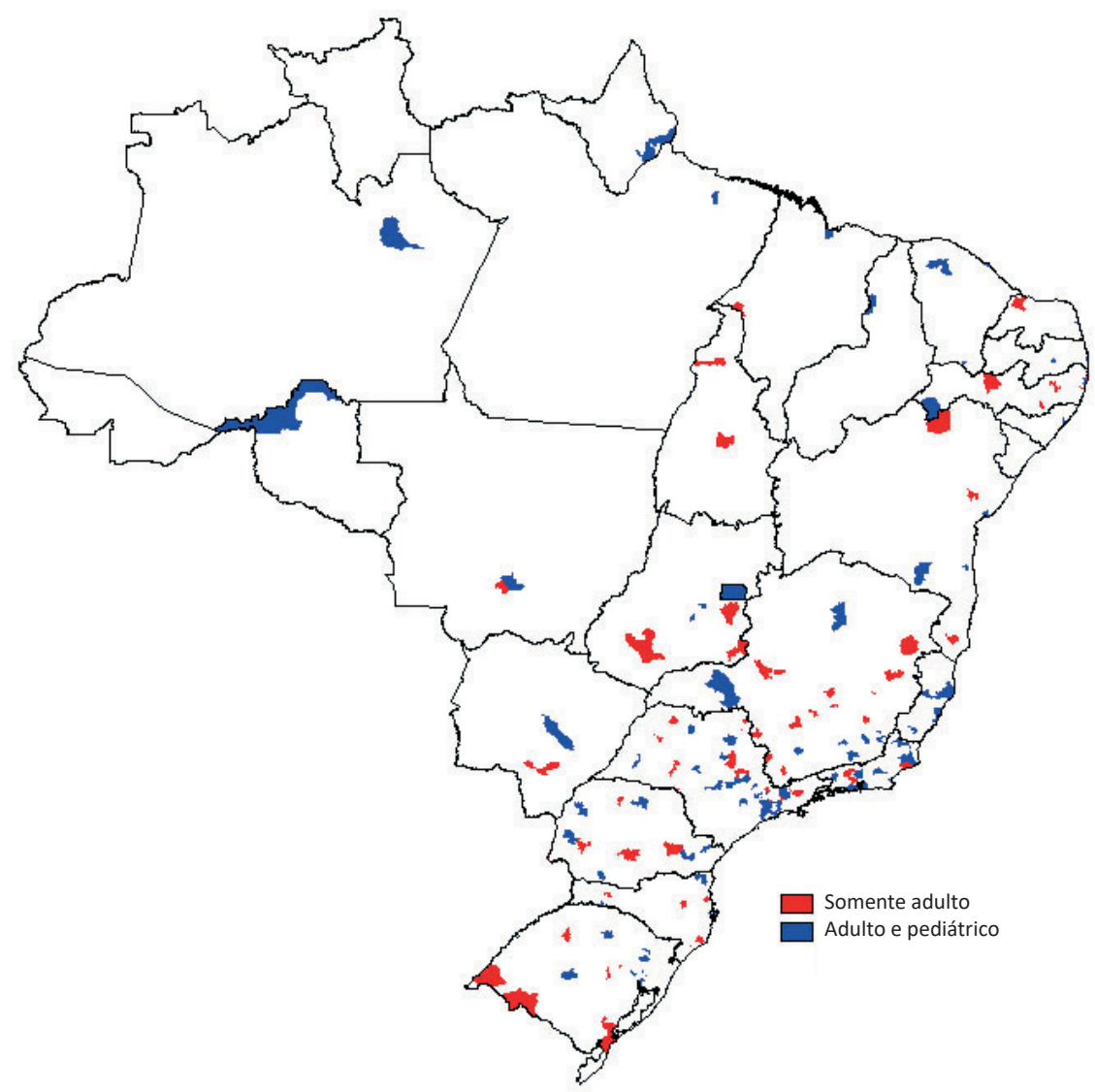

Fonte: elaborado pelas autoras, com base em dados do CNES referentes ao ano de 2013 (Brasil, 2014).

Gráfico 11 - Serviços habilitados para cirurgia cardíaca, por natureza jurídica. Brasil - 2013

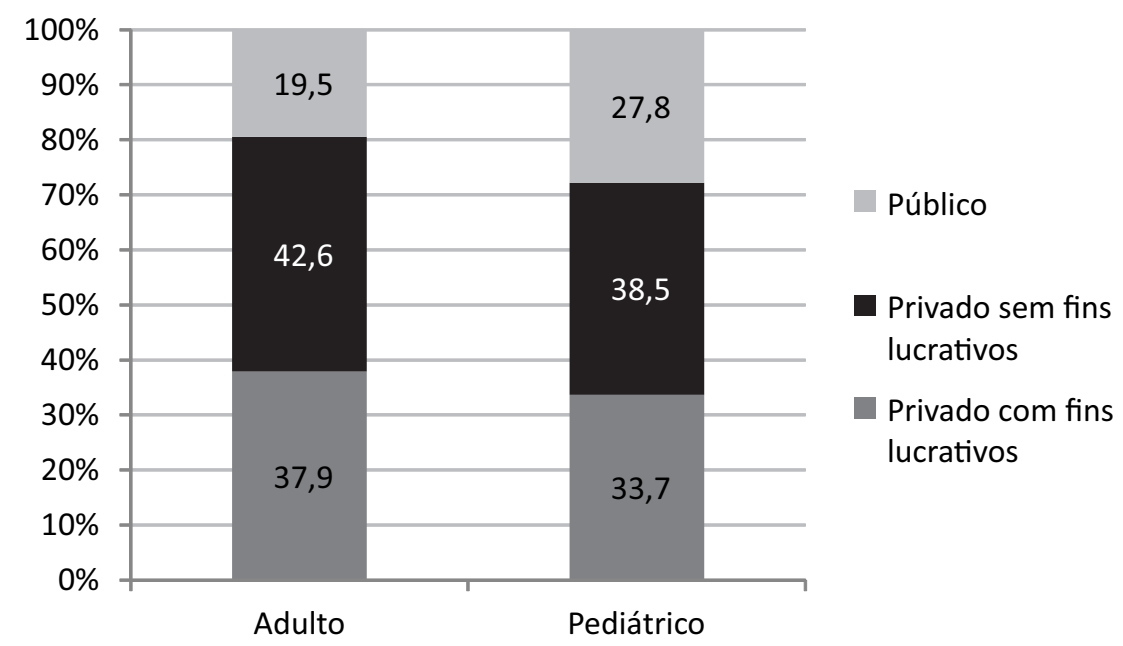

Fonte: elaborado pelas autoras, com base em dados do CNES referentes ao ano de 2013 (Brasil, 2014). 
Observa-se a existência de estabelecimentos com serviço de cirurgia cardíaca sem todas as estruturas necessárias para a realização de cirurgias de mais alta complexidade e risco: $36 \%$ dos serviços de cirurgia cardíaca pediátrica não contavam com UTI pediátrica, 6\% dos serviços de cirurgia cardíaca adulto sem UTI adulto, 31\% dos serviços totais sem dispor de raios X para hemodinâmica, e 27\% dos serviços totais não tinham equipamento de circulação extracorpórea (Gráfico 12).

Gráfico 12 - Serviços de cirurgia cardíaca segundo deficiências. Brasil - 2013

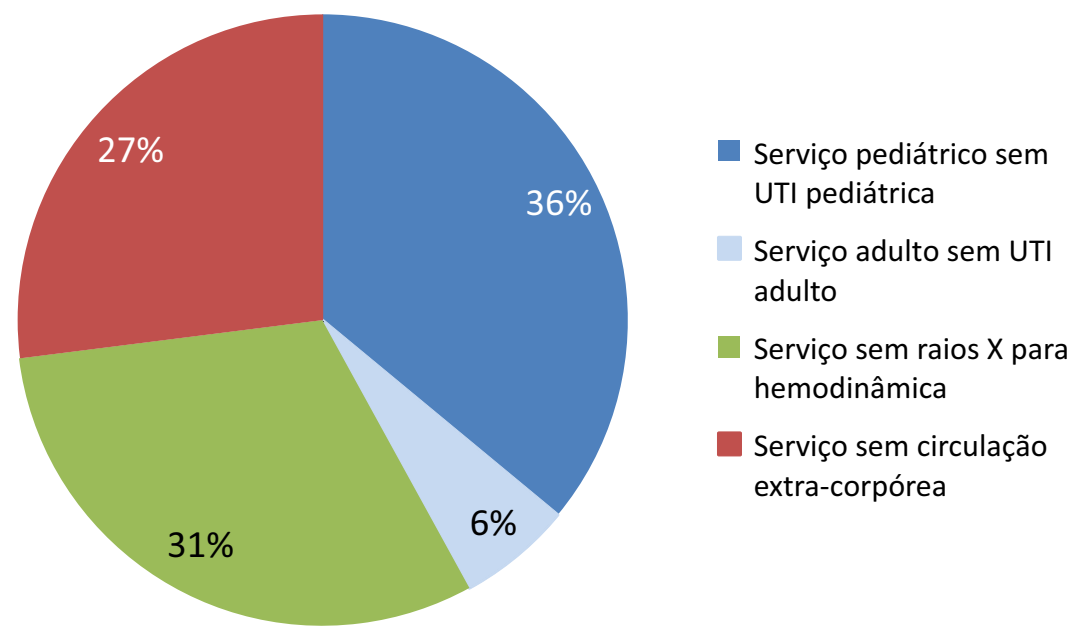

Fonte: elaborado pelas autoras, com base em dados do CNES referentes ao ano de 2013 (Brasil, 2014).

\section{Considerações Finais}

No fim de 2013, o Sistema de Saúde Brasileiro contava com 112.300 unidades de saúde, entre públicas, privadas sem fins lucrativos e privadas com fins lucrativos, segundo informações do CNES. Dessas, mais de 44 mil eram postos e centros de saúde, majoritariamente públicos, cerca de 41 mil policlínicas e clínicas especializadas e vinte mil unidades para SADT, em sua maioria privadas com fins lucrativos, mais de seis mil hospitais gerais e especializados em proporções semelhantes de vinculação aos setores públicos e privados com fins lucrativos, e cerca de mil prontos-socorros, em grande parte públicos.

Por um lado, os desafios relacionados às mudanças nos padrões sociodemográficos e epidemiológicos observados no Brasil geram impactos importantes sobre o planejamento e a organização da rede de atenção à saúde, envolvendo as unidades SUS e Não SUS.

Por outro lado, as invenções ${ }^{4}$ no campo da genômica, da bioengenharia, dos insumos e medicamentos, bem como das tecnologias de processo, que no século passado demoravam a se transformar

\footnotetext{
${ }^{4}$ Consideramos invenção o ato de criar uma nova tecnologia, processo ou objeto, ou um aperfeiçoamento de tecnologias, processos e objetos preexistentes.
} 
em inovação, ${ }^{5}$ hoje chegam ao mercado e são incorporadas nas unidades de saúde com enorme velocidade, desafiando-as em seus processos de transformação física.

Todos esses desafios têm influência tanto na definição dos investimentos em novas estruturas como na regulação e reorganização das estruturas existentes, que é o principal ponto com o qual buscamos contribuir com subsídios para o processo de planejamento e reorganização da rede de saúde do SUS.

Em relação a essa rede SUS, segundo diagnóstico do Primeiro Seminário de Gestão de Tecnologias e Inovação em Saúde, ocorrido em fevereiro de 2009, apesar dos avanços do SUS os problemas de gestão da saúde são ainda significativos. Uma das questões mais importantes se refere ao desenvolvimento tecnológico baseado na transferência de tecnologia e realizado quase sempre de forma incompleta. Ou seja, não é acompanhado por modificações que permitam a apropriação daquela tecnologia pela rede de saúde, envolvendo sua adaptação à situação organizacional, econômica, social e cultural do país e do sistema de saúde local.

Esse fato, além de encarecer os serviços de saúde, aumenta o risco à integridade do usuário da tecnologia e compromete a relação de complementaridade entre a estrutura pública e a privada de serviços de saúde, pois:

Saúde, ciência e tecnologia são requisitos para o desenvolvimento econômico e social (...) os países em desenvolvimento (...) terão de organizar sistemas de pesquisa em saúde baseados em prioridades sanitárias e assegurar a incorporação dos resultados às políticas e ações de saúde. Avanços na área biomédica, em particular em genômica, abrem novas oportunidades, mas impõem desafios adicionais (Morel, 2004: 261).

Assim, cada vez mais se torna necessária maior articulação entre as políticas de saúde e as políticas de educação, econômica, industrial, comercial e de ciência e tecnologia, de modo a reduzir a dependência tecnológica na área da saúde e promover a pesquisa e o desenvolvimento de bens que atendam às necessidades de saúde da população brasileira. Nesse mister, ainda segundo Morel:

Levar uma descoberta à sociedade, ou seja, transformar uma invenção em inovação, é um processo extremamente complexo e que depende do desempenho dos chamados sistemas nacionais de inovação. Há que se considerar não só as etapas estritamente pós-invenção (desenvolvimento tecnológico, ensaios pré-clínicos e clínicos, registro pelas agências reguladoras, fabricação e distribuição), mas também o sistema legal, o de propriedade intelectual e o regulador, assim como os mecanismos de financiamento. (...) Precisa-se, sobretudo, de clara decisão política (Morel, 2004).

Em relação à incorporação na rede de saúde brasileira de tecnologias ofertadas ao mercado desde a década de 1990, observou-se baixa complexidade na maior parte da rede do país, ilustrada em especial pela organização das unidades hospitalares, nas quais, das 6.641 existentes, aproximadamente 80\% dispunham de menos de 100 leitos, o que gera problemas relacionados a escala. Dessas unidades, 13\% tinham menos que 12 leitos; 47\% entre 13 e 49 leitos; 15\% entre 50 e 79 leitos; 5\% entre 80 e 99 leitos; $11 \%$ entre 111 a 299 leitos; e apenas $2 \%$ dos estabelecimentos apresentavam mais de 300 leitos.

${ }^{5}$ Consideramos inovação aquela invenção que chega no mercado. 
No caso específico dos leitos de UTI, a fim de responder às novas demandas de forma resolutiva, especialistas no tema indicam que a proporção de leitos de UTI, hoje estabelecida em portaria ministerial entre $4 \%$ e $10 \%$, tende a aumentar em razão das mudanças discutidas, devendo ainda nesta década alcançar 30\% dos leitos de hospitais de alta complexidade. Além disso, por meio de estudos, revela-se maior efetividade de unidades hospitalares com mais de cem leitos, em que a escala imprime qualidade e segurança. Uma importante questão que se coloca, pois, é a de como conciliar essas diretrizes com a realidade existente, em que o montante de $80 \%$ da rede hospitalar brasileira oferece menos de cem leitos e $61 \%$ menos de cinquenta leitos?

Em relação à complexidade dos recursos físicos disponibilizados, observa-se desequilíbrio entre a oferta de leitos SUS (disponíveis ao SUS) e Não SUS (não disponíveis ao SUS, ou seja, disponíveis ao pagamento privado direto ou por meio de planos privados de saúde), inclusive com diferenças proporcionais entre eles quando focalizada a participação dos leitos de UTI: a relação leitos UTI/ leitos gerais SUS era de 6\%, ao passo que essa relação nos leitos Não SUS era de 14\%.

Além do desequilíbrio entre leitos SUS e Não SUS e de um percentual muito baixo dos leitos de UTI em relação aos leitos existentes, existem grandes vazios na oferta dos leitos de UTI, com variações regionais: 5\% dos leitos da região Norte eram de UTI e na região Sul eram 8\%.

Em relação ao total de hospitais, 794 ofereciam UTI neonatal e estavam distribuídos em 284 municípios, e em quase a metade dos hospitais os serviços de UTI neonatal disponibilizavam entre seis e dez leitos. No caso dos leitos de UTI infantil, eram 605 hospitais que dispunham desse tipo de leito, distribuídos em 226 municípios, e quase a metade com menos de cinco leitos.

Em relação aos leitos de UTI adulto, estavam presentes em 1.690 hospitais, distribuídos em 224 municípios, em situação melhor do que as anteriores. Em 44\% dos hospitais os serviços de UTI para adultos tinham de seis a dez leitos e em 42\% dispunham de mais de 11 leitos, imprimindo maior complexidade aos recursos físicos existentes, caso existam os demais recursos necessários para a oferta desses serviços à população.

Algumas conclusões, se aprofundadas, como o caso da relação de leitos de UTI SUS e Não SUS, podem ser explicadas pelo mercado de venda de serviços ao SUS, e na relação de poder local, que investe no setor privado com garantia de venda ao SUS.

Entretanto, essa dificuldade na incorporação de tecnologias disponibilizadas ao mercado já há duas ou três décadas também pode ser explicada pela insuficiência quantitativa e qualitativa de profissionais para operar e manter tais tecnologias, como já destacado anteriormente.

Em relação às possibilidades de novas incorporações para atender tanto à transição sociodemográfica como à epidemiológica, diversos municípios dispunham de unidades de saúde com quase todas as estruturas necessárias para atender às condições analisadas. Potenciais investimentos nessas unidades poderiam contribuir para a criação de novos centros de atendimento a tais condições, diminuindo a distância entre a situação atual e a situação desejada.

No entanto, esse tema exige estudo detalhado, envolvendo especialistas, planejadores e gestores que explorem as características locais mais relevantes para o processo de mudança de complexidade 
e resolutividade da atenção provida por determinado município, com sustentabilidade. Por exemplo, a nosso ver, em relação ao trauma, os projetos de investimentos deveriam concentrar-se nas áreas onde há maior incidência de causas externas, associados à existência de trabalhadores para os novos recursos físicos incorporados, recursos de custeio para insumos e serviços, e inserção na malha local, por meio das pactuações necessárias ao credenciamento, transformando o investimento, realmente, em ampliação e/ou transformação da oferta.

A seguir destacaremos alguns aspectos que consideramos relevantes nos resultados apresentados para as condições analisadas: trauma de alta e média complexidade, doenças cardíacas e doenças renais.

\section{Trauma de alta e média complexidade}

Apenas 41 hospitais em trinta municípios estavam provistos das oito condições necessárias para serem habilitados como centro de referência em trauma de alta complexidade: ter mais de cem leitos, dispor de UTI, de tomografia computadorizada, de ressonância magnética, de assistência de alta complexidade em neurocirurgia (incluindo neurocirurgia e traumatologia), de hemoterapia, de radiologia intervencionista e de reabilitação.

Em 99 estabelecimentos de 64 municípios, encontraram-se sete das oito estruturas analisadas. E se escolhermos um estabelecimento por município que tenha maior estrutura disponível em sete das oito analisadas, chegamos a cinquenta dos 99 estabelecimentos com déficit de apenas uma das estruturas analisadas, o que poderia orientar a alocação de recursos para incorporação da tecnologia deficitária. Com isso, o Brasil mais que dobraria o número de municípios com capacidade de assistência ao trauma de alta complexidade, passando de trinta para oitenta municípios cobertos, uma grande mudança no perfil da oferta de serviços que atendem a importante demanda.

Destaca-se que a oferta de recursos físicos para a emergência em trauma é majoritariamente feita pelo SUS, uma vez que dos 41 hospitais com as oito estruturas, 17 são públicos, 21 são privados sem fins lucrativos e três privados com fins lucrativos. O mesmo padrão pode ser observado para a média complexidade, pois entre os 99 estabelecimentos com sete das oito estruturas, 34 são públicos, 56 privados sem fins lucrativos e nove privados com fins lucrativos.

\section{Doenças renais}

Dos 21 mil equipamentos para hemodiálise cadastrados no CNES, cerca de 19,9 mil estão informados como equipamentos em uso. Esses últimos estão distribuídos em 404 municípios, destacando-se com maior número nos municípios de São Paulo, Rio de Janeiro, Belo Horizonte, Recife, Fortaleza e Brasília, evidenciando uma concentração desses recursos físicos.

O desequilíbrio segundo natureza jurídica das unidades de saúde, já demonstrado no presente trabalho, também ficou patente nas análises no caso da hemodiálise, em que a maior parte dos equipamentos disponíveis no país está em unidades privadas com fins lucrativos. 


\section{Doenças cardíacas}

Em torno de 60\% do total de leitos clínicos e cirúrgicos destinados para doenças cardíacas estavam vinculados ao SUS, o que mostra que a população tem uma forte dependência desses serviços por parte do setor privado. Ao contrário do que se pensa, a doença coronariana é cada vez mais incidente nas populações de baixa renda, para as quais há menos disponibilidade de assistência, com ainda precária disponibilidade de serviços do SUS especializados nessa área (Marmot et al., 1999; Lynch et al., 2006). Com mais de $40 \%$ da oferta de leitos cardíacos vinculada ao setor privado, constitui uma área da assistência com grande potencial de gerar lucros para o setor privado, com o risco de, se o SUS continuar com esse grau de dependência da oferta do setor privado, ter de pagar os valores mais caros (de mercado) para esses serviços. Por exemplo, a hemodinâmica, por estar sendo oferecida cada vez mais pelo setor privado, vem seguindo a tendência da hemodiálise.

\section{Olhando o futuro}

Os caminhos para as transformações a serem realizadas nos recursos físicos de saúde para as próximas décadas, de modo a ajustar a capacidade às necessidades sociodemográficas e epidemiológicas e às ofertas tecnológicas disponibilizadas pelo desenvolvimento e pelas inovações tecnológicas são desafiadores.

No fim do século passado e nestas primeiras décadas do século XXI, incorporar tecnologias e/ ou reorganizar a oferta de recursos físicos, sobretudo no âmbito das unidades de saúde públicas, traduz-se em um processo complexo, que esbarra em trâmites burocráticos e torna lenta a conclusão do investimento. É neste contexto, de busca constante pelos avanços do futuro para o planejamento e o projeto do presente, que se inserem os estudos prospectivos.

Segundo Martin (1995), os estudos prospectivos se distanciam da ideia de previsão, quando se apresentam como processos coletivos que se repetem continuamente e seguem sofisticados rituais metodológicos. A atitude, o objetivo e o método fazem a diferença porque mesmo admitindo o risco de erro, o erro também é de natureza diversa, uma vez que neste caso o processo incorpora a mudança de opinião no próprio método e exige acompanhamento, contrachecagem e revisão permanente.

A opinião coletiva, a autorizada mudança de opinião e o caráter de permanência do processo dão maior credibilidade ao resultado, pelo menos até que se produza um novo que o atualize ou corrija. A concepção de prospecção (foresight) como processo a identifica como sendo uma

tentativa sistemática de olhar no longo prazo para o futuro em ciência, tecnologia, na economia e na sociedade, com o objetivo de identificar áreas estratégicas e as tecnologias genéricas emergentes com potencial para produzir os grandes benefícios econômicos e sociais. (Martin, 1995: 140)

Conforme Caruso e Tigre (2004), a prospecção tecnológica pode ser entendida ainda como um meio sistemático de mapear desenvolvimentos científicos e tecnológicos futuros capazes de influenciar de forma significativa uma indústria, a economia ou a sociedade como um todo. Diferentemente das atividades de previsão clássica, que se dedicam a antecipar um futuro suposto como único, os exercícios de prospecção são construídos a partir da premissa de que são vários os futuros possíveis. 
Com base no suposto que as ações presentes alteram o futuro, como ocorre com a inovação tecnológica, avanços tecnológicos futuros dependem de modo complexo e imprevisível de decisões alocativas tomadas no presente por um conjunto relativamente grande de agentes. Os exercícios de prospecção, então, funcionam como meio de atingir dois objetivos:

- preparar os atores na indústria para aproveitar ou enfrentar oportunidades ou ameaças futuras e;

- desencadear um processo de construção, no presente, de um futuro desejável.

Nesse sentido podemos pensar que o sucesso na introdução de novas tecnologias depende fundamentalmente da capacidade das organizações de absorver eficientemente novos equipamentos, sistemas e processos produtivos. Isso inclui a incorporação de novas rotinas, procedimentos e informações técnicas que, para serem efetivamente adotados, dependem da capacidade dos recursos humanos de transformar informação em conhecimento. Assim, a difusão de novas tecnologias está diretamente associada ao desenvolvimento de novas capacidades cognitivas para solucionar problemas na introdução, otimização e adaptação de tecnologias específicas ao ambiente de trabalho.

A análise prospectiva em geral se apoia na premissa da complexidade e na necessidade de explorar e entender essa teia de relações complexas, para então estabelecer possíveis alternativas de futuro. Ocorre que em muitos casos as técnicas empregadas não distinguem graus de hierarquias entre as variáveis, setores e eventos, ou seja, não consideram o caráter sistêmico das relações entre esses elementos, tornando difícil a criação de um marco lógico sobre o passado e o presente, que possa apoiar a formulação de hipóteses de futuros plausíveis. Alguns argumentos podem variar, mas no caso da tecnologia há certa convicção de que o elevado custo do investimento em ciência e tecnologia e a falta de recursos no setor público exigem fazer escolhas.

$\mathrm{Na}$ área da saúde, essas escolhas assumem dimensão de políticas públicas quando inseridas nas questões da necessidade de incorporação cotidiana de tecnologias nos hospitais gerais e especializados, centros de saúde e hospitais de alta complexidade no SUS, desta forma,

caberá ao gestor do sistema de saúde tomar decisões que têm efeitos práticos, partindo da constatação de que os recursos efetivamente disponíveis são de fato escassos, e da premissa de que seja moralmente legítimo proceder a alguma forma de 'racionamento' na alocação. (Schramm, 2000: 45)

Para os resultados de pesquisa de fato subsidiarem a tomada de decisão e a elaboração de políticas públicas mais adequadas para resolver as necessidades de oferta de recursos físicos de saúde, deverão necessariamente contemplar uma abordagem intersetorial. Nesse caso, não estamos falando apenas dos setores tradicionais como educação, cultura, meio ambiente etc., mas das realidades de cada município como potencial polo de cada serviço.

A ideia de investir em recursos físicos de saúde passa tanto pela necessidade de saúde da população, como pela capacidade da região de manter essa oferta. Por exemplo, a decisão de investir na aquisição de determinado recurso em um município requer a existência de pessoas capacitadas tanto para operarem esse recurso (médicos/especialidade médica, enfermeiros, técnicos de laboratório, físicos etc.) como para mantê-lo (tecnólogo biomédico, técnicos de elétrica etc.) em perfeito estado de funcionamento garantindo qualidade, segurança e efetividade do serviço prestado à população. 
Nesse contexto, para o cotejamento entre novas ofertas de recursos físicos e possibilidades de recursos humanos, é necessária uma parceria do Ministério da Saúde com o Ministério da Educação para definição de programas de formação em quantidade, perfil e localização estratégicos para a reorganização do sistema de saúde.

É por tal motivo que todo investimento deverá ser previamente analisado diante da complexa realidade do local de oferta, uma vez que essa realidade orientará se o investimento deverá ser para a aquisição de novos recursos - sejam novos ou realocados, vindos de outros municípios que não têm as condições necessárias para ofertar o recurso - ou para o conserto, manutenção e/ou criação de estrutura de serviços no intuito de oferecer determinado recurso físico. Com isso, a recomendação é que, inicialmente, seria oportuno ter a garantia de que os recursos existentes nominados pelo CNES estejam realmente em uso. Pode ser mais interessante para o país colocar em uso o que já existe, mesmo que necessite de alguma reestruturação ou realocação, pela migração dos recursos de um local para outro, do que realizar investimentos de aquisição de novos recursos ou unidades, por exemplo.

\section{Referências}

AGÊNCIA NACIONAL DE SAÚDE SUPLEMENTAR (ANS). Resolução Normativa - RN n. 42, de 4 de julho de 2003. Estabelece os requisitos para a celebração dos instrumentos Jurídicos firmados entre as operadoras de planos de assistência à saúde e prestadores de serviços hospitalares. Rio de Janeiro: ANS, 2003.

AGÊNCIA NACIONAL DE SAÚDE SUPLEMENTAR (ANS). Resolução Normativa - RN n. 85, de 7 de dezembro de 2004. Dispõe sobre a concessão de Autorização de Funcionamento das Operadoras de Planos de Assistência à Saúde, e dá outras providências. Rio de Janeiro: ANS, 2004.

BARRETO, M. L. Esboços para um cenário das condições de saúde da população brasileira 2022/2030. In: GADELHA, P.; CARVALHO, J. N. \& PEREIRA, T. R. (Orgs.). A Saúde no Brasil em 2030: diretrizes para a prospeç̧ão estratégica do sistema de saúde brasileiro. Rio de Janeiro: Fiocruz, Ipea, Ministério da Saúde, Secretaria de Assuntos Estratégicos da Presidência da República, 2013.

BRASIL. Ministério da Saúde. Portaria GM/MS n. 376 de 03 de outubro de 2000. Aprova a Ficha Cadastral dos Estabelecimentos de Saúde e o Manual de Preenchimento, bem como a criação do Banco de Dados Nacional de Estabelecimentos de Saúde. Brasília, Diário Oficial da União, 2000a.

BRASIL. Ministério da Saúde. Portaria GM/MS n. 511 de 29 dez. 2000. Determina o recadastramento de Estabelecimentos de Saúde. Brasília, Diário Oficial da União, 2000b.

BRASIL. Ministério da Saúde. Portaria SE/SAS n. 55 de 29 ago. 2001. Alteram procedimentos das tabelas SUS segundo o regulamento técnico para o funcionamento dos serviços de diálise e as normas para cadastramento desses serviços junto ao Sistema Único de Saúde. Brasília, Diário Oficial da União, 2001.

BRASIL. Ministério da Saúde. Portaria GM 2.048 de 5 nov. 2002. Aprova o Regulamento Técnico dos Sistemas Estaduais de Urgência e Emergência. Brasília, Diário Oficial da União, 2002.

BRASIL. Ministério da Saúde. Portaria n. 1168/GM de 15 jun. 2004. Institui a Política Nacional de Atenção ao Portador de Doença Renal, a ser implantada em todas as unidades federadas, respeitadas as competências das três esferas de gestão. Brasília, Diário Oficial da União, 2004a.

BRASIL. Ministério da Saúde. Portaria n. 210 de 15 jun. 2004. Define Unidades de Assistência em Alta Complexidade Cardiovascular e os Centros de Referência em Alta Complexidade Cardiovascular e suas aptidões e qualidades. Brasília, Diário Oficial da União, 2004b. 
BRASIL. Ministério da Saúde. Secretaria de Atenção à Saúde. Reforma do Sistema da Atenção Hospitalar Brasileira. Brasília: Ministério da Saúde, 2004c.

BRASIL. Ministério da Saúde. Portaria n. 1.366, de 8 jul. 2013. Estabelece a organização dos Centros de Trauma, estabelecimentos de saúde integrantes da Linha de Cuidado ao Trauma da Rede de Atenção às Urgências e Emergências (RUE) no âmbito do Sistema Único de Saúde (SUS). Brasília, Diário Oficial da União, 2013.

BRASIL. Ministério da Saúde. Secretaria de Atenção à Saúde. Cadastro Nacional dos Estabelecimentos de Saúde do Brasil - CNES, 2014. Disponível em:<http://cnes.datasus.gov.br/>. Acesso em: 21 jun. 2017.

CARUSO, L. A. \& TIGRE, P. B. (Orgs.). Modelo Senai de Prospecção: documento metodológico. Montevideo: OIT, Cinterfor, 2004.

CARVALHO, C. A. Cadastro Nacional de Estabelecimentos de Saúde - CNES: seu desenvolvimento, implantação e uma proposta para sua manutenção, 2004. Dissertação de Mestrado, Rio de Janeiro: Escola Nacional de Saúde Pública Sérgio Arouca, Fundação Oswaldo Cruz.

CAZELLI, C. M. et al. Análise das desigualdades regionais na oferta de serviços de saúde no Brasil: pesquisa da assistência médico-sanitária, 1992 e 1999. Saúde em Debate, 26(61): 198-209, 2002.

CONGRESSO mineiro de ortopedia debate fraturas nos idosos. Medicina \& Saúde. Belo Horizonte, 21 jul. 2014. Disponível em: < http://www.portalmedicinaesaude.com.br/blog_single50.html >. Acesso em: 19 fev. 2017.

COSTA, N. R. \& COSTA, L. F. P. Avaliação de programa de atenção à saúde: incentivo à oferta de atenção ambulatorial e a experiência da descentralização no Brasil. Ciência \& Saúde Coletiva, 7(4): 907-923, 2002.

LA FORGIA, G. M. \& COUTTOLENC, B. F. Desempenho Hospitalar no Brasil: em busca da excelência. São Paulo: Singular, 2009.

INSTITUTO BRASILEIRO DE GEOGRAFIA E ESTATÍSTICA (IBGE). Estatísticas da Saúde. Assistência Médicosanitária 2009. Rio de Janeiro: IBGE, 2010. Disponível em: < http://www.ibge.gov.br/home/estatistica/ populacao/condicaodevida/ams/2009/ams2009.pdf>. Acesso em: 26 abr. 2014.

KUSCHNIR, R. \& CHORNY, A. H. Redes de atenção à saúde: contextualizando o debate. Ciência \& Saúde Coletiva, 15(5): 2.307-2.316, 2010.

LUNA, E. J. A. \& SILVA JUNIOR, J. B. Doenças Transmissíveis, Endemias, Epidemias e Pandemias. In: GADELHA, P.; CARVALHO, J. N. \& PEREIRA, T. R. (Orgs.). A Saúde no Brasil em 2030: diretrizes para a prospecção estratégica do sistema de saúde brasileiro. Rio de Janeiro: Fiocruz, Ipea, Ministério da Saúde, Secretaria de Assuntos Estratégicos da Presidência da República, 2013.

LYNCH, J. et al. Explaining the social gradient in coronary heart disease: comparing relative and absolute risk approaches. Journal of Epidemiology and Community Health, 60(5): 436-441, 2006.

MACHADO, J. P. O Arranjo Público-Privado no Brasil e a Qualidade da Assistência Hospitalar em São Paulo e no Rio Grande do Sul, 2014. Tese de Doutorado, Rio de Janeiro: Escola Nacional de Saúde Pública Sérgio Arouca, Fundação Oswaldo Cruz.

MARMOT, M. G. et al. Health inequalities among British civil servants: the Whitehall II study. The Lancet, 337(8.754): 1.387-1.393, 1999.

MARTIN, B. R. Foresight in science and technology. Echnology Analysis \& Strategic Management, 7(2): 139-167, 1995.

MENDES, A. C. G. et al. Assistência pública de saúde no contexto da transição demográfica brasileira: exigências atuais e futuras. Cadernos Saúde Pública, 28(5): 955-964, 2012.

MOREL, C. M. A pesquisa em saúde e os objetivos do milênio: desafios e oportunidades globais, soluções e políticas nacionais. Ciência \& Saúde Coletiva, 9(2): 261-270, 2004. 
MOREL, C. M. Alguns países em desenvolvimento, entre eles o Brasil, têm alcançado grandes avanços em inovação tecnológica. Entrevista à Agência Fiocruz de Notícias. Jornal da Ciência. Rio de Janeiro, 4 ago. 2005. Disponível em: <www.jornaldaciencia.org.br/edicoes/?url=http://jcnoticias.jornaldaciencia.org.br/category/ pdf/> . Acesso em: 23 out. 2014.

NASCIMENTO, E. G. Q. A Importância do Cadastro Nacional de Estabelecimentos de Saúde (CNES) como Instrumento na Auditoria em Saúde, 2012. Monografia de Especialização, Curitiba: Faculdades Pequeno Príncipe.

OLIVEIRA, A. T. R. \& ONEILL, M. M. V. C. Cenário sociodemográfico em 2022/2030 e distribuição territorial da população: uso e ocupação do solo. In: GADELHA, P.; CARVALHO, J. N. \& PEREIRA, T. R. (Orgs.). A Saúde no Brasil em 2030: diretrizes para a prospecção estratégica do sistema de saúde brasileiro. Rio de Janeiro: Fiocruz, Ipea, Ministério da Saúde, Secretaria de Assuntos Estratégicos da Presidência da República, 2013.

ORGANIZAÇÃO PAN-AMERICANA DA SAÚDE (OPAS). Rede Interagencial de Informação para a Saúde. Indicadores básicos para a saúde no Brasil: conceitos e aplicações. Brasília: Opas, 2008.

PAIM, J. et al. O Sistema de Saúde Brasileiro: história, avanços e desafios. The Lancet, 11-31, 2011. (Série Saúde no Brasil 1)

PESSÔA, L. R. Terceirização nos Hospitais Públicos: mais um problema ou uma possível solução, 1996. Dissertação de Mestrado, Rio de Janeiro: Escola Nacional de Saúde Pública Sérgio Arouca, Fundação Oswaldo Cruz.

PESSÔA, L. R. Mergulho em Montes Claros: desafios da alocação de recursos na rede SUS, 2005. Tese de Doutorado, Rio de Janeiro: Escola Nacional de Saúde Pública Sergio Arouca, Fundação Oswaldo Cruz.

PESSÔA, L. R. (Org.). Unidade de Aprendizagem Arquitetura e Engenharia. Rio de Janeiro: EAD, Ensp/Fiocruz, 2009.

RODRIGUES, C. G; AMARAL, P. V. M. \& SIMÕES R. F. Rede urbana da oferta de saúde: uma análise multivariada macrorregional - Brasil, 2002. Revista de Desenvolvimento Econômico, 9(16): 1.516-1.684, 2007.

SANTOS, I. S.; SANTOS, M. A. B. \& BORGES, D. C. L. Mix público-privado no sistema de saúde brasileiro: realidade e futuro do SUS. In: GADELHA, P.; CARVALHO, J. N. \& PEREIRA, T. R. (Orgs.). A Saúde no Brasil em 2030: diretrizes para a prospecção estratégica do sistema de saúde brasileiro. Rio de Janeiro: Fiocruz, Ipea, Ministério da Saúde, Secretaria de Assuntos Estratégicos da Presidência da República, 2013.

SANTOS, I. S.; UGÁ, M. A. D. \& PORTO, S. M. O mix público-privado no sistema de saúde brasileiro: financiamento, oferta e utilização de serviços de saúde. Ciência \& Saúde Coletiva, 13(5): 1.431-1.440, 2008.

SCHRAMM, F. R. Bioética, economia e saúde: direito à assistência, justiça social, alocação de recursos. Revista Brasileira de Cancerologia, 46(1): 41-47, 2000.

TRIBUNAL DE CONTAS DA UNIÃO (TCU). Relatório de Levantamento - FiscSaúde (TC 032.624/2013-1). Brasília: TCU, 2013. Disponível em: <https://contas.tcu.gov.br/juris/Web/Juris/ConsultarTextual2/Index. faces?textoPesquisa $>$. Acesso em: 4 maio 2014.

VECINA NETO, G; MALIK, A. M. Tendências na assistência hospitalar. Ciência \& Saúde Coletiva, 12(4): 825-839, 2007.

VIACAVA, F. \& BAHIA, L. Oferta de Serviços de Saúde: uma análise da pesquisa assistência médico-sanitária (AMS) de 1999. Brasília: Ipea, 2002. (Texto para discussão n. 915) 


\section{ANEXO}

Quadro 1 - Resultado da auditoria do TCU em amostra de hospitais

\begin{tabular}{|c|c|}
\hline $\begin{array}{l}\% \text { DAS UNIDADES } \\
\text { VISITADAS }\end{array}$ & PRINCIPAIS PROBLEMAS APONTADOS PELOS GESTORES \\
\hline \multicolumn{2}{|r|}{ RECURSOS HUMANOS } \\
\hline $81 \%$ & Apresentam deficit no quadro de pessoal (médicos,enfermeiros, outros). \\
\hline $81 \%$ & $\begin{array}{l}\text { Falta de pessoal é o problema para bloqueio de leitos ( } 47 \% \text { do total de leitos } \\
\text { bloqueados). }\end{array}$ \\
\hline $63 \%$ & Absenteísmo dos profissionais provoca impactos à prestação de serviços. \\
\hline \multicolumn{2}{|r|}{$\begin{array}{c}\text { MEDICAMENTOS E INSUMOS } \\
\text { (medicamentos, roupas hospitalares, seringas, ataduras, fios cirúrgicos) }\end{array}$} \\
\hline $56 \%$ & $\begin{array}{l}\text { Falta ou insuficiências por falhas em licitações (deficiência na estimativa de } \\
\text { quantitativos). }\end{array}$ \\
\hline $53 \%$ & Carência de instrumentos de gestão (controle de solicitação, saída e distribuição). \\
\hline $48 \%$ & Falta de instrumentos ou mobiliário básico para prestação de serviços. \\
\hline $39 \%$ & Desperdício por práticas inadequadas dos profissionais. \\
\hline \multicolumn{2}{|r|}{$\begin{array}{l}\text { EQUIPAMENTOS } \\
\text { (monitores, ventiladores pulmonares, tomógrafos,mamógrafos) }\end{array}$} \\
\hline $77 \%$ & $\begin{array}{l}\text { Bloqueio de leitos por falta de equipamentos mínimos ( } 11 \% \text { do total de leitos } \\
\text { bloqueados). }\end{array}$ \\
\hline $59 \%$ & Atendimento inadequado em função de equipamentos antigos ou desatualizados. \\
\hline $45 \%$ & Ausência ou deficiência de contratos de manutenção. \\
\hline $22 \%$ & $\begin{array}{l}\text { Equipamentos de alto custo não utilizados ou subutilizados por falta de } \\
\text { profissionais. }\end{array}$ \\
\hline \multicolumn{2}{|r|}{ ESTRUTURA FÍSICA E MANUTENÇÃO PREDIAL } \\
\hline $73 \%$ & Estrutura física inadequada e/ou falta de manutenção predial. \\
\hline $59 \%$ & Principal motivo para bloqueio de leitos (18\% do total de leitos bloqueados). \\
\hline $45 \%$ & Contrato de manutenção predial não atende a todas as necessidades da unidade. \\
\hline $25 \%$ & Não possuem local adequado para guarda de cadáveres. \\
\hline
\end{tabular}

Fonte: TCU, 2013. 